\title{
Lycium barbarum polysaccharide protects rats and cardiomyocytes against ischemia/reperfusion injury via Nrf2 activation through autophagy inhibition
}

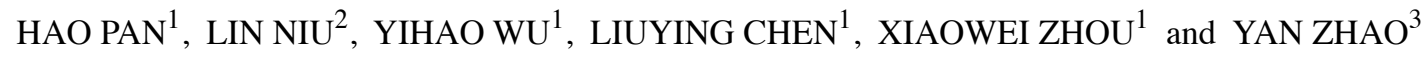 \\ Departments of ${ }^{1}$ Cardiology and ${ }^{2}$ Ultrasound, Affiliated Hangzhou First People's Hospital, \\ Zhejiang University School of Medicine, Hangzhou, Zhejiang 310006; ${ }^{3}$ Department of Cardiology, \\ Zhejiang Provincial People's Hospital, People's Hospital of Hangzhou Medical College, \\ Hangzhou, Zhejiang 310014, P.R. China
}

Received May 17, 2021; Accepted July 23, 2021

DOI: $10.3892 / \mathrm{mmr} .2021 .12418$

\begin{abstract}
The irreversible loss of cardiomyocytes is mainly the result of ischemic/reperfusion (I/R) myocardial injury, leading to persistent heart dysfunction and heart failure. It has been reported that Lycium barbarum polysaccharide (LBP) has protective effects on cardiomyocytes, but the specific mechanism is still not completely understood. The present study examined the protective role of LBP in myocardial I/R injury. Rats were subjected to myocardial I/R injury and LBP treatment. Moreover, rat myocardial H9C2 cells exposed to hypoxia/reoxygenation (H/R) were used to simulate cardiac injury during myocardial I/R process and were exposed to LBP, rapamycin (an autophagy activator) or nuclear factor-erythroid factor 2-related factor 2 (Nrf2) transfection. Morphological examination, histopathological examination and echocardiography were used to determine the cardiac injury after I/R injury. Cell viability and apoptosis were determined via MTT and flow cytometry assays, respectively. The levels of lactate dehydrogenase ( $\mathrm{LDH})$, creatine kinase (CK), cardiac troponin T (cTnT), IL-1 $\beta$, IL-6, TNF- $\alpha$, malondialdehyde (MDA) and superoxidase dismutase (SOD) in rat serum, hearts and/or cells were assessed using ELISAs. The expression levels of Beclin 1, LC3II/LC3I, P62 and Nrf2 were analyzed via reverse transcription-quantitative $\mathrm{PCR}$ and western blotting. The results demonstrated that LBP improved heart function and repaired cardiomyocyte damage in I/R model rats, as well as reduced the production of cTnT, CK, LDH, IL-1 $\beta$, IL- 6 and
\end{abstract}

Correspondence to: Dr Yan Zhao, Department of Cardiology, Zhejiang Provincial People's Hospital, People's Hospital of Hangzhou Medical College, 158 Shangtang Road, Chaohui, Xiacheng, Hangzhou, Zhejiang 310014, P.R. China

E-mail: zhaoyan_zhy1@163.com

Key words: Lycium barbarum polysaccharide, myocardial ischemia/reperfusion injury, nuclear factor-erythroid factor 2-related factor 2, autophagy
TNF- $\alpha$. The in vitro study results indicated that LBP increased cell viability, the apoptosis rate, and the levels of SOD and P62, as well as reduced the levels of LDH, CK, IL-1 $\beta$, IL- 6 , TNF- $\alpha$, MDA, Beclin 1 and LC3-II/LC3-I in H/R-injured H9C2 cells. Moreover, LBP promoted Nrf2 nuclear translocation, but decreased Nrf2 expression in the cytoplasm. Rapamycin exacerbated the aforementioned effects in H/R injured H9C2 cells, and partially reversed LBP-induced effects. Overexpressing Nrf2 counteracted I/R-induced effects and partially resisted rapamycin-induced effects. These findings demonstrated that LBP exhibited a cardiac protective effect on the ischemic myocardium of rats after reperfusion and attenuated myocardial I/R injury via autophagy inhibition-induced Nrf2 activation.

\section{Introduction}

Myocardial ischemia/reperfusion (I/R) injury, referring to aggravated tissue injury or irreversible injury in myocardial ischemic tissues following the reperfusion of blood flow (1), is associated with serious clinical manifestations, including myocardial hibernation, myocardial infarction and acute heart failure (2), and is thus marked as a risk factor for morbidity and mortality (3). The application of reperfusion in I/R aims at restoring blood flow, through which oxygen is provided to ischemic tissues that present with hypoxia and hypoperfusion caused by the obstruction of arterial blood flow (4). However, reperfusion itself can trigger a cascade of pathophysiological reactions that contribute to the expansion of the infarct area, accounting for up to $50 \%$ of the final infarct size of the ischemic myocardium (5). Despite the advances in the therapeutic strategies (6), the onset of $\mathrm{I} / \mathrm{R}$ injury remains high during several common clinical conditions, such as coronary bypass surgery, thrombolytic therapy, cardiopulmonary resuscitation or organ transplantation $(7,8)$. It has been shown that the pathological mechanism of $\mathrm{I} / \mathrm{R}$ is associated with decreased ATP production and increased reactive oxygen species (ROS) retention, which leads to profound inflammatory responses that further induce the apoptosis, necrosis and autophagy of cardiomyocytes $(4,9)$. 
Lycium barbarum polysaccharide (LBP), characterized by the composition of glucose monosaccharides and fructose monosaccharides at a molar level of 1:2, is an active constituent extracted from Lycium barbarum, the fruit of which is used in the practice with traditional Chinese medicine (10). Various studies have reported the pharmacological and biological effects of LBP, including antioxidative (11), immune-regulatory (12), anti-cancer (13), neuroprotective (14) and blood sugar/lipid-lowering properties (15). Notably, LBP is documented to exert cardio-protective effects against I/R-caused damage in vivo by reducing the levels of myocardial lactate dehydrogenase (LDH), increasing sodium-potassium ATPase and calcium ATPase activities, and repressing the apoptosis of cardiomyocytes (10). Moreover, LBP can attenuate cardiac hypertrophy, and decrease the levels of certain inflammatory factors, such as IL- 6 and TNF- $\alpha$, as well as lower the production of ROS in heart tissues of diabetic rats (16). However, the detailed mechanism via which LBP protects against $\mathrm{I} / \mathrm{R}$-induced injury in cardiomyocytes remain unknown.

$\mathrm{Xiao}$ et al (15) revealed that the autophagic process modulated by LBP attenuated hepatic inflammatory responses and cell apoptosis in rats with non-alcoholic steatohepatitis. Autophagy is an evolutionarily conserved mechanism in charge of controlling intracellular protein and organelle via lysosome-dependent degradation (17). The key regulatory factors of autophagy are Beclin-1, LC3 and sequestosome 1 (SQSTM1 or P62, one of the particular substrate protein of autophagosome). Beclin 1, a mammalian ortholog of yeast Atg6, mediates the formation of autophagosomes and, thus, contributes to autophagy initiation (18). The conversion of LC3-I to LC3-II is an important autophagy marker. (19). Furthermore, a decrease in P62 induces the formation of autolysosomes. Under normal conditions, autophagy stays at basal level in the heart; however, dysregulated and enhanced autophagy is observed during the occurrence of cardiovascular diseases, such as myocardial I/R injury (20). Accordingly, reducing excessive I/R injury-induced autophagy via trimetazidine inhibits myocardial apoptosis and oxidative stress, diminishes myocardial infarct area and restores cardiac function (21). Additionally, nuclear factor-erythroid factor 2-related factor 2 (Nrf2) in adenocarcinoma alveolar basal epithelial (A549) cells is negatively associated with autophagy induced by particulate matter (PM) 2.5 (22).

Therefore, the present study aimed to investigate and evaluate the efficacy and mechanism of LBP in myocardial I/R injury, where the involvement of autophagy and its relationship with Nrf2 were also elucidated.

\section{Materials and methods}

Ethics statement. All animal experiments were performed in accordance with the Guidelines for the Care and Use of Laboratory Animals (23). This study was approved by the Ethic Committee of Experimental Animals of Zhejiang Provincial Animal Center (approval no. DC201901203; Hangzhou, China). Every effort was made to minimize pain and discomfort to the animals. The animals experiments were performed in Zhejiang Provincial Animal Center.

Establishment of $I / R$ rat models. In total, 24 male Sprague-Dawley rats, aged 7-8 weeks old and weighing
250-280 g, were purchased from Shanghai SLAC Laboratory Animal Co., Ltd., and housed in controlled conditions $\left(22-25^{\circ} \mathrm{C}, 55 \%\right.$ humidity and a $12: 12 \mathrm{~h}$ circadian cycle). All rats were fed ad libitum with commercial food and sterile water in Zhejiang Provincial Animal Center, and were acclimated for 2 days prior to the commence of the experiment. Rats were then randomly assigned into four groups $(n=6$ for each group): Sham group, LBP group, I/R group and I/R + LBP group. LBP (purity, 51.87\%) was obtained from Xi'an Natural Field Bio-Technique Co., Ltd. The specific steps of the extraction of the LBP were as follows: The deionized water extract of Lycium barbarum was filtered through filter paper to eliminate dregs. After being concentrated to the volume under vacuum, the crude extract was diluted to deionized water, precipitated with $95 \%$ ethanol, followed by precipitation and centrifugation $\left(3,000 \mathrm{x}\right.$ g for $25 \mathrm{~min}$ at $\left.4^{\circ} \mathrm{C}\right)$. Finally, LBP (the precipitate) was harvested and minced into powder.

The specific treatment of rats in each group is listed in Fig. 1A. The rats in the LBP and I/R + LBP groups were treated with $500 \mathrm{mg} / \mathrm{kg} /$ day $\operatorname{LBP}(24,25)$ for 7 days (once a day) via oral administration (26), before sham operation and myocardial I/R injury, respectively. Those in the Sham group and I/R group received $0.9 \%$ sodium chloride in the same manner. On the 8th day, the rats were anesthetized via an intraperitoneal injection of $1.5 \%$ tribromoethanol ( 250 mg/kg; cat. no. T48402; Sigma-Aldrich; Merck KGaA). After successful anesthesia, the rats were placed in the supine position on the animal operating table. For the induction of ischemia, the chest of each rat was opened through a left parasternal incision, and the heart exposed at the left 3rd-4th intercostal space. Then, the left anterior descending coronary artery 1.5-2 $\mathrm{mm}$ below left atrial appendage was ligated by tying a slipknot with 5/0 silk sutures. The heart was repositioned into the chest, the blood and gas in the chest were then squeezed out, and the chest was closed quickly. After $30 \mathrm{~min}$ of induction, the slipknot was untied and the myocardium underwent the reperfusion for $120 \mathrm{~min}$. The rats in the sham operation group underwent the same surgical operation, but the coronary artery was not ligated. After $120 \mathrm{~min}$ of reperfusion, each rat was anesthetized as aforementioned, and transthoracic echocardiography was performed. Then, all rats were sacrificed via dislocation under anesthesia. Subsequently, the blood of the rats was collected from the abdominal aorta and the serum obtained via centrifugation (at $1,500 \mathrm{x} \mathrm{g}$ for $10 \mathrm{~min}$.) was stored at $-80^{\circ} \mathrm{C}$ for further analysis. The hearts of rats were harvested and rinsed with ice-cold PBS (cat. no. P4417; Sigma-Aldrich; Merck KGaA), and the ventricular tissues were immediately stored at $-80^{\circ} \mathrm{C}$.

Evaluation of rat heart function. After $2 \mathrm{~h}$ of reperfusion, transthoracic echocardiography was performed using an ultrasonic imaging system (Vevo 1100; FUJIFILM VisualSonics, Inc.). The two-dimensional B-mode and M-mode traces were collected along the short axis of the left ventricle. Left ventricular end-systolic diameter (LVEDs), left ventricular end-diastolic diameter (LVEDd), ejection fraction (EF) and fractional shortening (FS) were analyzed offline using the advanced cardiovascular measurements package (Vevo 770; VisualSonics, Inc.) in a blinded manner. 
A

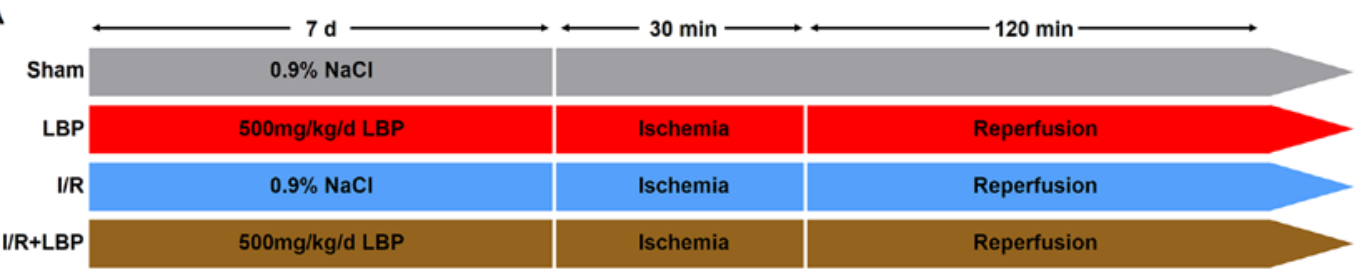

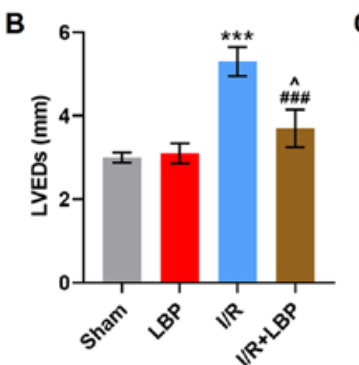

F

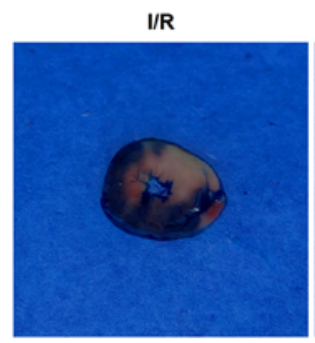

I

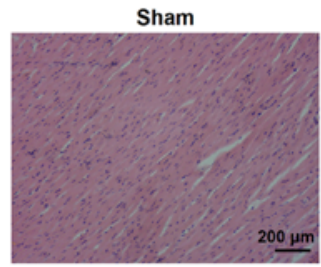

J

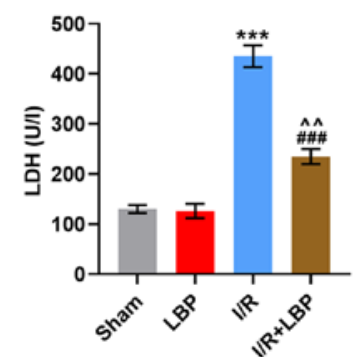

M

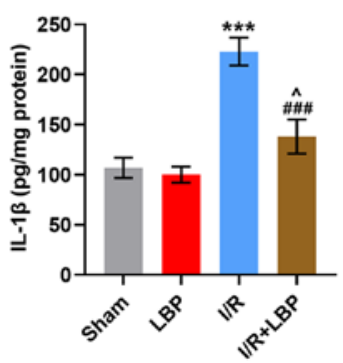

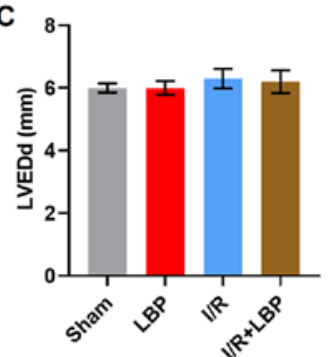
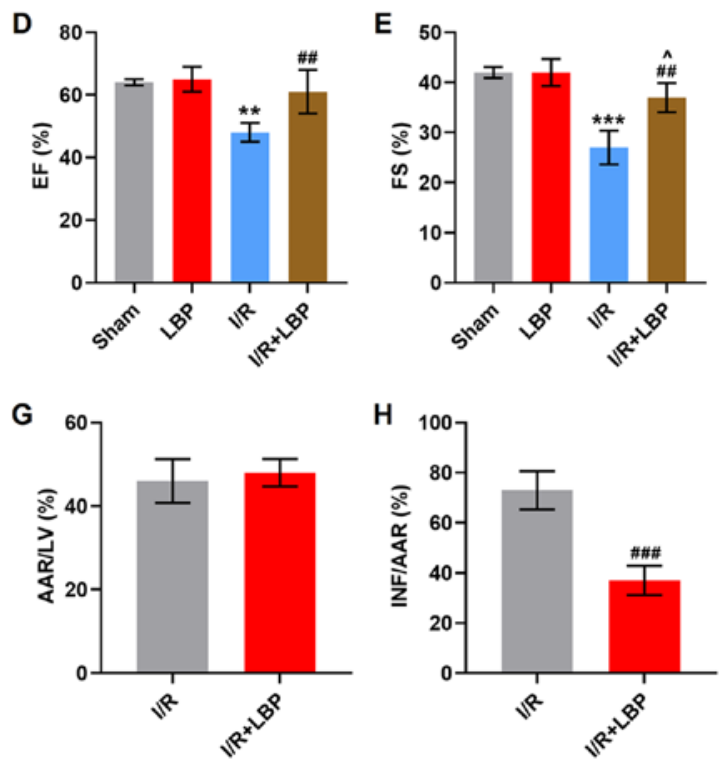

LBP
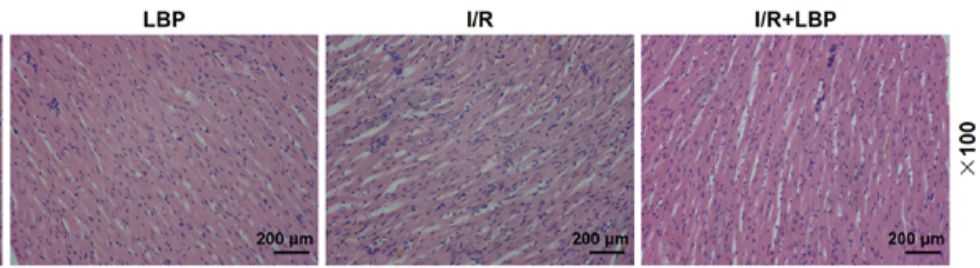

K
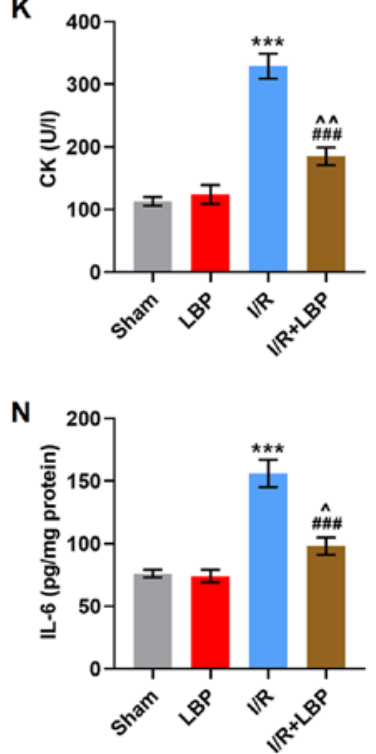

L
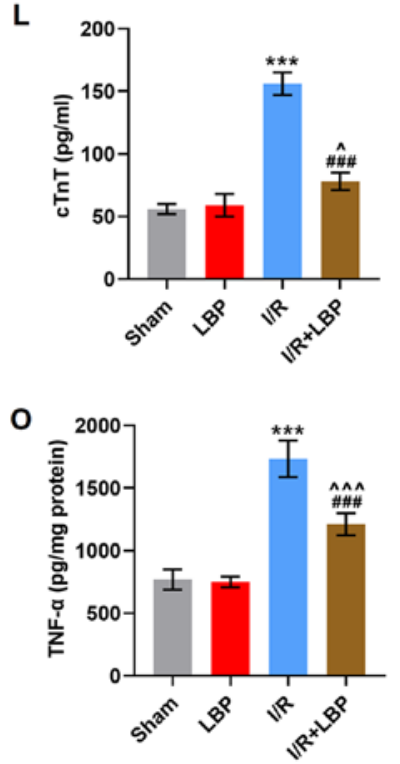

Figure 1. LBP counteracts I/R-induced heart malfunction, histopathological abnormalities and inflammation in rats. (A) A diagram of the establishment of the I/R model and LBP treatment. (B) LVEDs, (C) LVEDd, (D) EF and (E) FS in I/R- and LBP-treated rats were determined via transthoracic echocardiography. (F) Representative images of heart sections of I/R-injured rats treated with LBP were analyzed via Evan's blue and 2,3,5-triphenyl-tetrazolium chloride double-staining. The percentages of $(\mathrm{G}) \mathrm{AAR} / \mathrm{LV}$ and $(\mathrm{H}) \mathrm{INF} / \mathrm{AAR}$ were estimated. AAR/LV reflects the extent of myocardial ischemia, while NF/AAR reflects the level of dead myocardium. (I) The histopathological changes in the heart of I/R-injured rats treated with LBP was examined via H\&E staining (scale bar, $200 \mu \mathrm{m}$; magnification, x100). The levels of (J) LDH, (K) CK, (L) cTnT, (M) IL-1ß, (N) IL-6 and (O) TNF- $\alpha$ in I/R-injured rats treated with LBP were measured using ELISAs. ${ }^{* *} \mathrm{P}<0.01,{ }^{* * *} \mathrm{P}<0.001$ vs. Sham; ${ }^{\wedge} \mathrm{P}<0.05,{ }^{\wedge} \mathrm{P}<0.01,{ }^{\wedge \wedge} \mathrm{P}<0.001$ vs. LBP; ${ }^{\# \#} \mathrm{P}<0.01,{ }^{\# \# \#} \mathrm{P}<0.001$ vs. I/R. Sham, rats received sham operation; I/R, ischemia/reperfusion; LBP, Lycium barbarum polysaccharide; LVEDs, left ventricular end-systolic diameter; LVEDd, left ventricular end-diastolic diameter; EF, ejection fraction; FS, fractional shortening; LDH, lactate dehydrogenase; CK, creatine kinase; AAR, area at risk; INF, infarcted area; LV, left ventricle. 
Evan's blue and 2,3,5-triphenyl-tetrazolium chloride (TTC) double-staining. After cannulation of the aorta, the hearts were perfused with 1\% Evan's blue solution (cat. no. G1810; Beijing Solarbio Science \& Technology Co., Ltd.) for $10 \mathrm{~min}$ at $37^{\circ} \mathrm{C}$. After being frozen for $20 \mathrm{~min}$, the hearts were transected into 2-mm thick sections and then stained with $1 \%$ TTC (cat. no. 17779; Sigma-Aldrich; Merck KGaA) at $37^{\circ} \mathrm{C}$ for $15 \mathrm{~min}$ in PBS. The analyzes of the size of the infarcted area (INF), area at risk (AAR) and the whole left ventricle (LV) were performed using ImageJ software (1.52s version; National Institutes of Health). The infarct size was presented as a ratio of INF to AAR.

$H \& E$ staining. After being fixed with $4 \%$ paraformaldehyde (cat. no. 16005; Sigma-Aldrich; Merck KGaA) at room temperature for $24 \mathrm{~h}$, dehydrated with gradient alcohol and transparentized using xylene (cat. no. 95682; Sigma-Aldrich; Merck KGaA), the ventricular tissues were paraffinized (cat. no. 1496904; Sigma-Aldrich; Merck KGaA) and sliced into $5-\mu \mathrm{m}$ thick sections, which were then dewaxed using xylene and rehydrated using gradient alcohol. Hematoxylin (cat. no. H3136; Sigma-Aldrich; Merck KGaA) was used to stain the sections at room temperature for $12 \mathrm{~min}$. Next, the sections were differentiated using hydrochloric alcohol and then stained with eosin (cat. no. E4009; Sigma-Aldrich; Merck KGaA) at room temperature for 5 min. Lastly, neutral balsam (cat. no. N861409; Shanghai Macklin Co., Ltd.) was used to seal the sections. After being dried at $37^{\circ} \mathrm{C}$ for $4 \mathrm{~h}$, the sections were observed and pathologically examined under an inverted microscope (ZEISS Primovert; Carl Zeiss AG) at x100 magnification.

Cell culture. Rat cardiomyocytes, $\mathrm{H} 9 \mathrm{C} 2$, were obtained from the American Type Culture Collection (ATCC; cat. no. CRL-1446), and cultured in ATCC-formulated DMEM (cat. no. 30-2002; ATCC) supplemented with 10\% FBS (cat. no. 30-2020; ATCC) at $37^{\circ} \mathrm{C}$ with $5 \% \mathrm{CO}_{2}$.

Cell transfection. Nrf2 overexpression plasmid was constructed using a pcDNA3.1 vector (cat. no. V79520; Thermo Fisher Scientific, Inc.), and its transfection into H9C2 cells was performed using Lipofectamine ${ }^{\circledR} 3000$ transfection reagent (cat. no. L3000015; Thermo Fisher Scientific, Inc.). Briefly, H9C2 cells were seeded at a density of $1 \times 10^{4}$ cells/well in 96-well plates. When the cells reached $80 \%$ confluence, Lipofectamine 3000 transfection reagent $(0.15 \mu \mathrm{l})$ and $\mathrm{Nrf} 2$ overexpression plasmid $(0.2 \mu \mathrm{g})$ were mixed with Opti-MEM (cat. no. 31985062; Thermo Fisher Scientific, Inc.) supplemented with $\mathrm{P} 3000$ reagent $(0.4 \mu \mathrm{g})$ and added into the cells, subsequent to which the cells were incubated with plasmid-lipid complex at $37^{\circ} \mathrm{C}$ for $48 \mathrm{~h}$. The empty pcDNA3.1 vector was served as a negative control (NC). After $48 \mathrm{~h}$ of transfection, cells were collected for further experiment.

Myocardial I/R cellular model construction and drug treatment. LBP (purity, 51.87\%) was diluted using PBS in order to prepare the working solutions with different concentrations $(15,30$ and $60 \mu \mathrm{g} / \mathrm{ml})$. To investigate the effects of LBP on myocardial I/R injury, H9C2 cells with or without transfection of Nrf2 overexpression plasmid underwent hypoxia via incubation with glucose-free serum in an anaerobic environ- ment $\left(1 \% \mathrm{O}_{2}, 5 \% \mathrm{CO}_{2}\right.$ and $\left.94 \% \mathrm{~N}_{2}\right)$ at $37^{\circ} \mathrm{C}$ for $24 \mathrm{~h}$. This was followed by subjection to the reoxygenation process under normoxic conditions $\left(21 \% \mathrm{O}_{2}, 5 \% \mathrm{CO}_{2}\right.$ and $\left.74 \% \mathrm{~N}_{2}\right)$ at $37^{\circ} \mathrm{C}$ for $4 \mathrm{~h}$. LBP $(15,30$ and $60 \mu \mathrm{g} / \mathrm{ml})$ or rapamycin (RAPA; an autophagy enhancer; $100 \mu \mathrm{mol} / \mathrm{l}$; cat. no. 37094; Sigma-Aldrich; Merck KGaA) were added at the start of reoxygenation at $37^{\circ} \mathrm{C}$ during the $4 \mathrm{~h}(27,28)$. To determine the interaction between LBP and RAPA, H9C2 cells received a combined treatment of LBP $(15 \mu \mathrm{g} / \mathrm{ml})$ and RAPA $(100 \mu \mathrm{mol} / \mathrm{l})$ at the start of reoxygenation at $37^{\circ} \mathrm{C}$ during the $4 \mathrm{~h}$.

Reverse transcription-quantitative $P C R$ (RT-qPCR). Total RNA from H9C2 cells was isolated using TRIzol ${ }^{\circledR}$ reagent (cat. no. 15596026; Thermo Fisher Scientific, Inc.). The total RNA used as templates for cDNA was reverse transcribed into cDNA using the SuperScript ${ }^{\mathrm{TM}}$ IV First-Strand Synthesis System (cat. no. 18091050; Thermo Fisher Scientific, Inc.) at $37^{\circ} \mathrm{C}$ for $10 \mathrm{~min}$. The amplification of cDNA was performed using a PCR detection device (CFX Connect; Bio-Rad Laboratories, Inc.) with PowerUp SYBR Green Master mix (cat. no. A25742; Thermo Fisher Scientific, Inc.). Primers for Nrf2 (forward, 5'-AAACCCAGTGTGACCAACGT-3' and reverse, 5'-GCACACGTGTGGTACTCAGA-3') and GAPDH (forward, 5'-TGGATAGGGTGGCCGAAGTA-3' and reverse, 5'-TACAAGGGGAGCAACAGCTG-3') were used. The thermocycling conditions were as follows: Initial denaturation at $95^{\circ} \mathrm{C}$ for $10 \mathrm{~min} ; 40$ cycle of denaturation at $95^{\circ} \mathrm{C}$ for $15 \mathrm{sec}$, and annealing and elongation at $60^{\circ} \mathrm{C}$ for $60 \mathrm{sec}$ without final extension. The relative expression levels of genes were calculated using the ${ }^{2-\Delta \Delta C q}$ method (29), and GAPDH was used as the internal reference.

Western blotting. Total protein from $\mathrm{H} 9 \mathrm{C} 2$ cells was extracted using RIPA buffer (cat. no. 89900; Thermo Fisher Scientific, Inc.) and the concentration was determined using a BCA kit (cat. no. A53227; Thermo Fisher Scientific, Inc.). The protein $(40 \mu \mathrm{g})$ and marker $(4 \mu \mathrm{l})$ (cat. no. PR1910; Beijing Solarbio Science \& Technology Co., Ltd.) were separately loaded and electrophoresed via 12\% SDS-PAGE (cat. no. P0672; Beyotime Institute of Biotechnology), followed by transfer onto PVDF membranes (cat. no. P2438; Sigma-Aldrich; Merck KGaA), which were blocked using 5\% skim milk in TBS with 1\% Tween-20 (TBST; cat. no. TA-125-TT; Thermo Fisher Scientific, Inc.) at room temperature for $1 \mathrm{~h}$. The membranes were then incubated at $4^{\circ} \mathrm{C}$ overnight with the primary antibodies for Nrf2 (cat. no. ab89443; 68 kDa; 1:1,000; Abcam), Beclin 1 (cat. no. ab207612; $52 \mathrm{kDa} ; 1: 2,000 ;$ Abcam), LC3-II/LC3-I (cat. no. ab48394; LC3-II, 17 kDa; LC3-I, $19 \mathrm{kDa} ; 1: 1,000$; Abcam), LaminA (cat. no. 4777; $74 \mathrm{kDa}$; 1:2,000; Cell Signaling Technology, Inc.) and GAPDH (cat. no. ab181602; $36 \mathrm{kDa} ; 1: 10,000$; Abcam). After being washed with TBST, the membranes were incubated with the HRP-conjugated secondary antibodies, including goat anti-rabbit IgG (cat. no. A32731; 1:10,000; Thermo Fisher Scientific, Inc.) or goat anti-mouse IgG (cat. no. A32733; 1:1,000, Thermo Fisher Scientific, Inc.). The protein bands were visualized using an ECL reagent kit (cat. no. WP20005; Thermo Fisher Scientific, Inc.) and the grey value of each band was analyzed with ImageJ software $(1.52 \mathrm{~s}$ version; National Institutes of Health). 
MTT assay. I/R-treated H9C2 cells were seeded at a density of $1 \times 10^{4}$ cells/well in 96-well plates with transfection, as well as treatment of LBP and RAPA in combination or alone. Then, $20 \mu 1$ MTT solution (cat. no. V900888; Sigma-Aldrich; Merck KGaA) was added and incubated with the cells at $37^{\circ} \mathrm{C}$ for $4 \mathrm{~h}$. Next, $100 \mu 1$ DMSO (cat. no. D2650; Sigma-Aldrich; Merck KGaA) was used to dissolve the formazan generated during the incubation. The absorbance at $570 \mathrm{~nm}$ was recorded using a microplate reader (ELx808; BioTek Instruments, Inc.).

Annexin-V/PI staining assay. Cell apoptosis was determined using an Annexin V-FITC/PI apoptosis detection kit (cat. no. E-CK-A211; Elabscience Biotechnology, Inc.). Briefly, the I/R-treated H9C2 cells with transfection, as well as treatment of LBP and RAPA in combination or alone, were digested using trypsin, centrifuged at $3,000 \times \mathrm{g}$ for $5 \mathrm{~min}$ at $4^{\circ} \mathrm{C}$ and then washed with PBS (twice for the processes of centrifugation and washing, respectively). Then, the cells were re-suspended using binding buffer and incubated with Annexin V-FITC solution (5 $\mu \mathrm{l})$ and PI solution $(10 \mu \mathrm{l})$ at room temperature for $15 \mathrm{~min}$ in the dark. Lastly, the cells were transferred to a flow cytometer (Cytoflex; Beckman Coulter, Inc.) and the apoptotic rates of the cells were analyzed using CytExpert software (version 2.2.0.97; Beckman Coulter, Inc.).

ELISA. The ventricular tissues and $\mathrm{H} 9 \mathrm{C} 2$ cells were centrifuged at $1,000 \mathrm{x} \mathrm{g}$ for $20 \mathrm{~min}$ at $4^{\circ} \mathrm{C}$ for the collection of supernatants. The levels of LDH (cat. no. JL13677-96T), creatine kinase (CK; cat. no. JL34658-96T), sera cardiac troponin T (cTnT; cat. no. JL18321-96T), IL-1 $\beta$ (cat. no. JL20884-96T), IL-6 (cat. no. JL20896-96T), TNF- $\alpha$ (cat. no. JL13202-96T), malondialdehyde (MDA; cat. no. JL13297-96T) and superoxidase dismutase (SOD; cat. no. JL22893-96T) in the supernatant were calculated using their corresponding ELISA kits (Jonln; http://www.jonln. com/), according to the manufacturer's instructions. Briefly, H9C2 cells with transfection, as well as treatment of LBP and RAPA in combination or alone, were centrifuged at $1,000 \mathrm{xg}$ for $20 \mathrm{~min}$ at $4^{\circ} \mathrm{C}$, and the supernatant was collected, $50 \mu \mathrm{l}$ of which was transferred to the enzyme-coated plates. Then, the HRP-labeled antibody $(50 \mu \mathrm{l})$ was added into the plates, which were incubated at $37^{\circ} \mathrm{C}$ for $60 \mathrm{~min}$. After being washed with the buffer solution $(350 \mu \mathrm{l})$ five times, the substrate reagent was added into the plates and the plates were further incubated at $37^{\circ} \mathrm{C}$ for $15 \mathrm{~min}$ in the dark. The reaction was terminated by the addition of sulfuric acid (in a final volume of $50 \mu \mathrm{l}$ ) and the optical density value was recorded with a microplate reader (ELx808; BioTek Instruments, Inc.) at $450 \mathrm{~nm}$.

Statistical analysis. Statistical analysis was performed using SPSS software (version 20.0; IBM Corp.). All data are expressed as the mean \pm SD. One-way ANOVA along with Tukey's post hoc test was used for comparison among multiple groups. $\mathrm{P}<0.05$ was considered to indicate a statistically significant difference. All experiments were repeated independently in triplicate.

\section{Results}

LBP counteracts $I / R$-induced heart malfunction, histopathological abnormalities and inflammation in rats. The transthoracic echocardiography analysis demonstrated that
I/R-treated rats exhibited increased LVEDs and declined EF and FS $(\mathrm{P}<0.01, \mathrm{P}<0.001$; Fig. 1B-E), while LVEDd remained unchanged. Moreover, LBP reversed the aforementioned changes $(\mathrm{P}<0.01, \mathrm{P}<0.001$; Fig. 1B-E). The results of Evan's blue and TTC double staining revealed that LBP significantly abrogated I/R-induced size increases of the infarct area, as suggested by the decreased INF/AAR ( $\mathrm{P}<0.001$; Fig. 1F-H). The histopathological examination via $H \& E$ staining identified that I/R-induced myocardial distortion and injury were alleviated by LBP (Fig. 1I).

As $I / R$ can induce cardiomyocyte damage along with the increase on the activities of enzymes, such as LDH and CK, inflammatory responses and oxidative stress (30-32), the levels of both enzymes and these corresponding factors were quantified in I/R-treated rats. As demonstrated in the analyses with ELISAs, the levels of LDH, CK, cTnT, IL-1 $\beta$, IL-6 and TNF- $\alpha$ were increased after the construction of the I/R model $(\mathrm{P}<0.001)$, while LBP treatment reversed these trends in rats with $\mathrm{I} / \mathrm{R}(\mathrm{P}<0.001$; Fig. $1 \mathrm{~J}-\mathrm{O})$. Thus, LBP may attenuate I/R-induced effects on these factors.

LBP counteracts the I/R-induced decrease of viability, promotion of apoptosis, cardiomyocyte damage, inflammation and oxidative stress in $\mathrm{H} 9 \mathrm{C} 2$ cells. The effects of LBP on cardiomyocytes were determined after the construction of cellular I/R model. Since the cytoprotective effects of LBP at different concentrations $(15,30$ and $60 \mu \mathrm{g} / \mathrm{ml})$ on oxygen glucose deprivation/reoxygenation-induced hippocampal neurons have been confirmed previously (27), the current study evaluated whether LBP could also protect H9C2 cells from I/R-induced injury at these concentrations. The result of MTT assay demonstrated that the construction of cellular I/R model decreased the viability of H9C2 cells $(\mathrm{P}<0.001)$, the trend of which was partially abrogated by $\operatorname{LBP}(15,30$ and $60 \mu \mathrm{g} / \mathrm{ml})$ treatment $(\mathrm{P}<0.05, \mathrm{P}<0.01$; Fig. $2 \mathrm{~A})$.

To determine the association between the apoptosis and the effects of LBP on I/R-treated cardiomyocytes, flow cytometry was conducted. It was found that a significantly increased apoptosis occurred after the construction of cellular I/R model $(\mathrm{P}<0.001)$, while LBP $(15,30$ and $60 \mu \mathrm{g} / \mathrm{ml})$ treatment partially reversed this enhancement induced by $\mathrm{I} / \mathrm{R}(\mathrm{P}<0.001$; Fig. 2B and C).

Serum levels of LDH and CK were assayed to assess cellular damage. The construction of the cellular I/R model was associated with the increased contents of $\mathrm{LDH}, \mathrm{CK}$ and MDA, the enhanced release of IL-1 $\beta$, IL- 6 and TNF- $\alpha$ and decreased SOD activity $(\mathrm{P}<0.001)$, while all of these I/R-induced changes were partially reversed by the treatment of LBP $(15,30$ and $60 \mu \mathrm{g} / \mathrm{ml})$, according to the results of ELISAs $(\mathrm{P}<0.05, \mathrm{P}<0.01$, $\mathrm{P}<0.001$; Fig. 2D-J). Taken together, these results suggested that LBP protects cardiomyocytes against I/R-induced decrease of viability, promotion of apoptosis, cardiomyocyte damage, inflammation and oxidative stress.

LBP inhibits I/R-induced autophagy in H9C2 cells. Autophagy in cardiomyocytes is demonstrated to be promoted in an anoxia duration-dependent manner in response to anoxia/reperfusion (28). Therefore, to investigate whether the protective effects of LBP on cardiomyocytes against I/R-induced injury were associated with the modulation of autophagy, the current study analyzed the expression levels of autophagy-related 
A

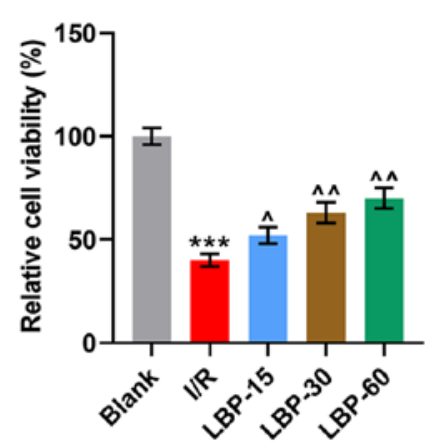

B

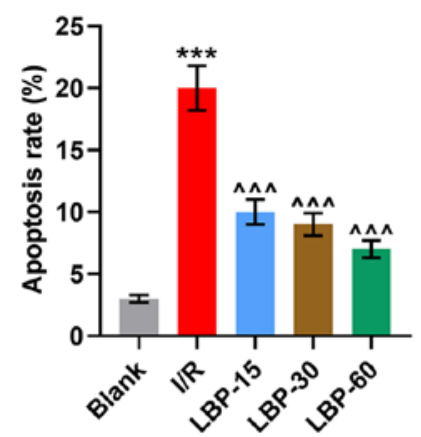

C
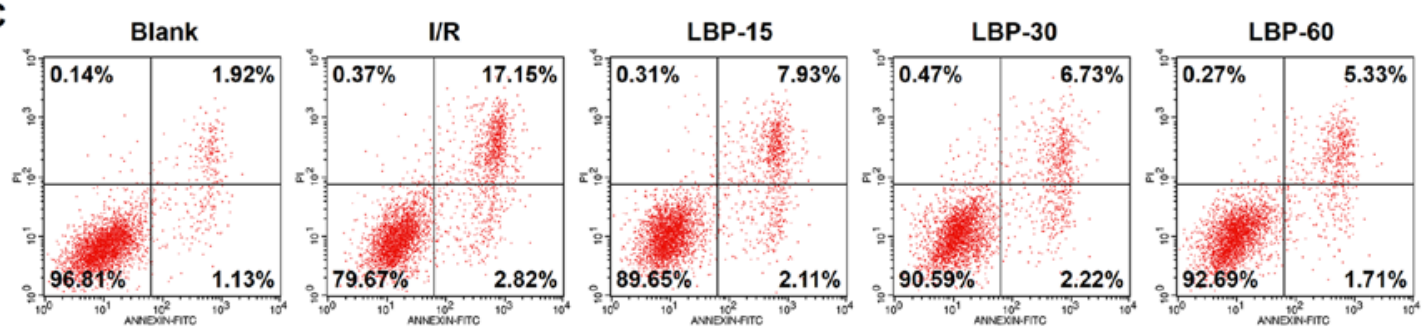

D

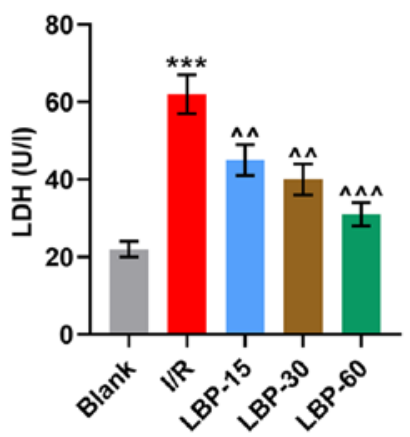

E

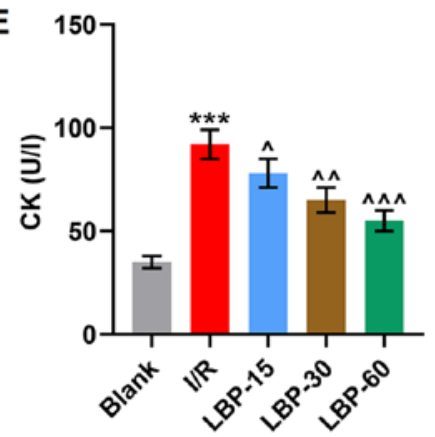

$\mathbf{F}$

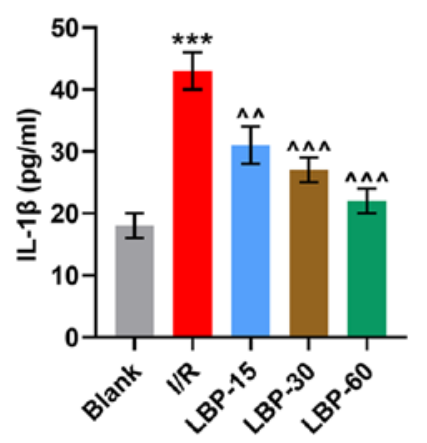

G

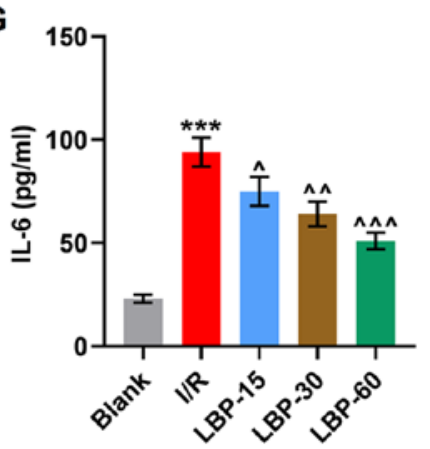

H

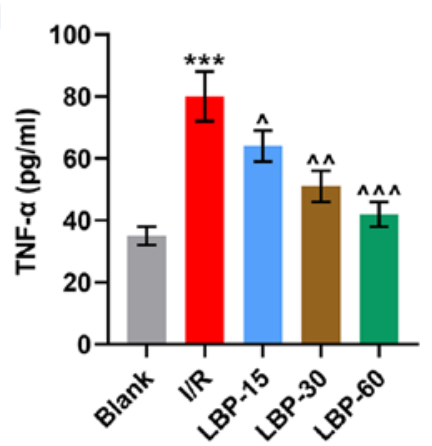

I

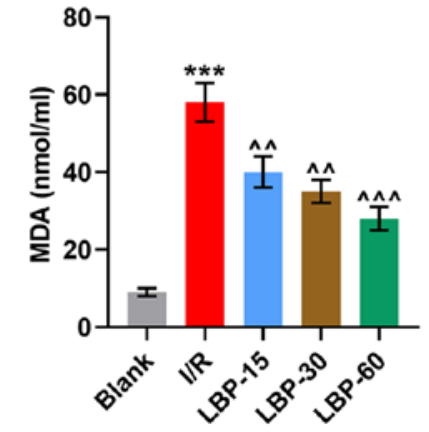

$\mathbf{J}$

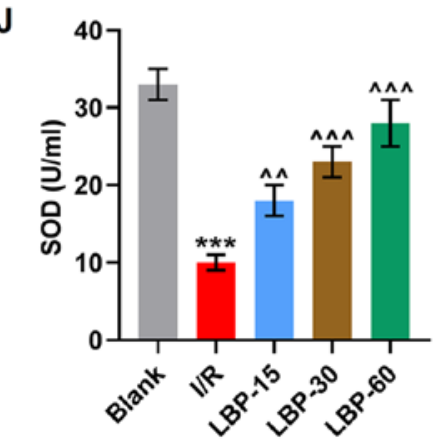

Figure 2. LBP counteracts I/R-induced decrease of viability, promotion of apoptosis, cardiomyocyte damage, inflammation and oxidative stress in H9C2 cells. (A). The viability of I/R-induced H9C2 cells treated with LBP (15, 30 and $60 \mu \mathrm{g} / \mathrm{ml})$ was determined using an MTT assay. (B) The apoptosis of I/R-induced H9C2 cells treated with LBP $(15,30$ and $60 \mu \mathrm{g} / \mathrm{ml})$ was determined via (C) flow cytometry. The levels of (D) LDH, (E) CK, (F) IL-1 $\beta$, (G) IL-6, (H) TNF- $\alpha$, (I) MDA and (J) SOD in I/R-induced H9C2 cells treated with $\mathrm{LBP}(15,30$ and $60 \mu \mathrm{g} / \mathrm{ml})$ were measured using ELISAs. ${ }^{* * *} \mathrm{P}<0.001 \mathrm{vs}$. Blank; ${ }^{\wedge} \mathrm{P}<0.05,{ }^{\wedge} \mathrm{P}<0.01$, ${ }^{\wedge \wedge} \mathrm{P}<0.001$ vs. I/R. I/R, ischemia/reperfusion; LBP, Lycium barbarum polysaccharide; LDH, lactate dehydrogenase; CK, creatine kinase; MDA, malondialdehyde; SOD, superoxidase dismutase. 
A

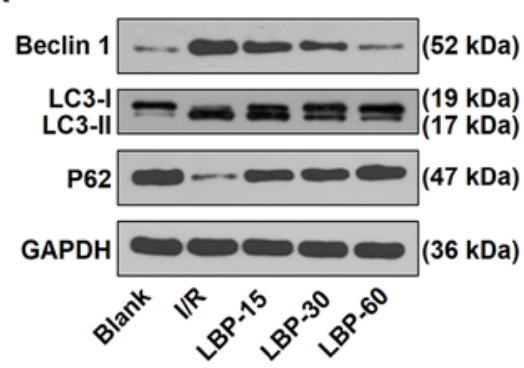

B

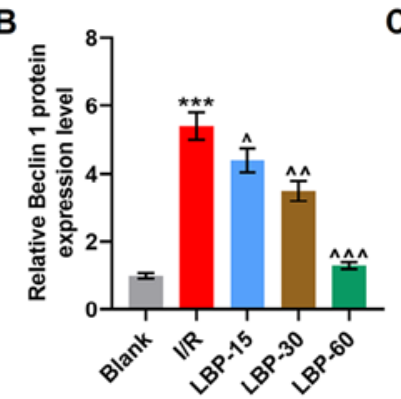

C

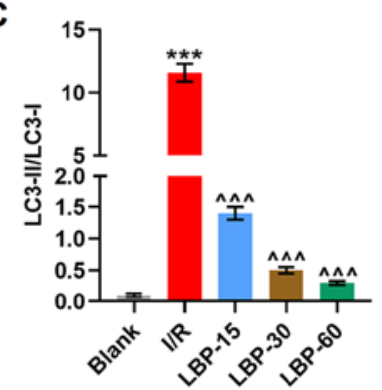

D

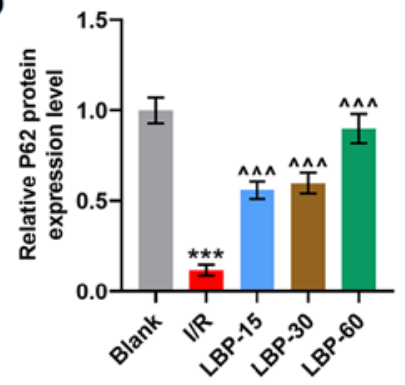

Figure 3. LBP inhibits I/R-induced autophagy in H9C2 cells. (A) Western blotting results of the protein expression levels of (B) Beclin 1, (C) LC3-II/LC3-I and (D) P62 in I/R-induced H9C2 cells treated with $\mathrm{LBP}(15,30$ and $60 \mu \mathrm{g} / \mathrm{ml})$, with GAPDH serving as an endogenous reference. ${ }^{* * *} \mathrm{P}<0.001 \mathrm{vs}$. Blank; ${ }^{\wedge} \mathrm{P}<0.05$, ${ }^{\wedge} \mathrm{P}<0.01,{ }^{\wedge \wedge} \mathrm{P}<0.001$ vs. I/R. I/R, ischemia/reperfusion; LBP, Lycium barbarum polysaccharide.

A

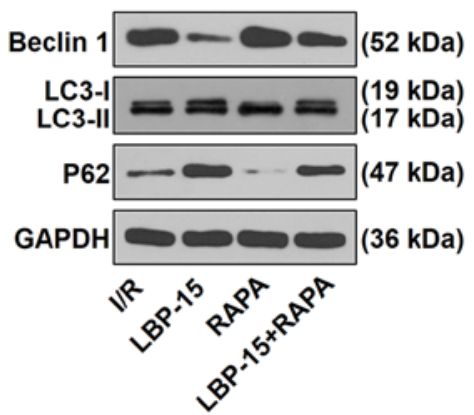

B

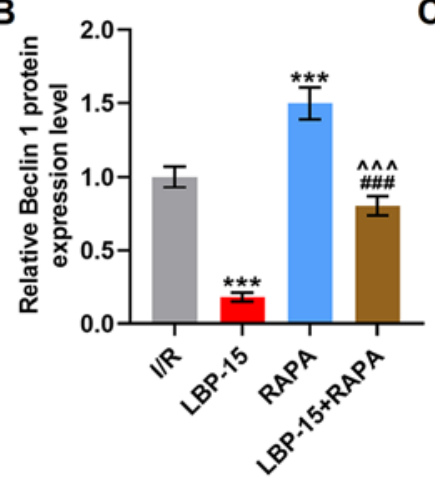

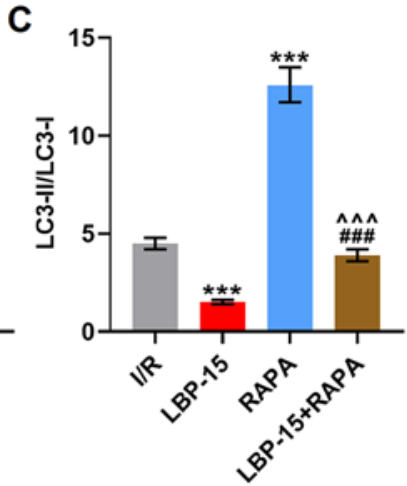

D

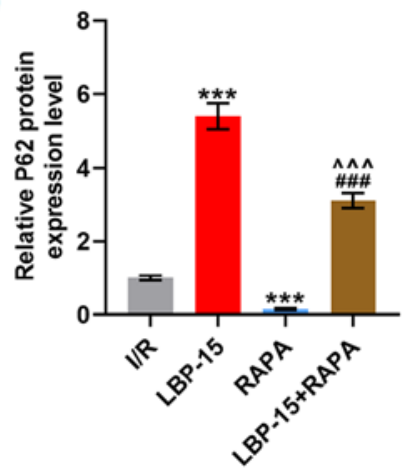

Figure 4. RAPA partially reverses LBP-induced inhibition of autophagy in I/R-induced H9C2 cells. (A) Western blotting results of the protein expression levels of (B) Beclin 1, (C) LC3-II/LC3-I and (D) P62 in I/R-induced H9C2 cells with the treatment of LBP (15 $\mu \mathrm{g} / \mathrm{ml})$ and RAPA in combination or alone, with GAPDH serving as an endogenous reference. ${ }^{* * *} \mathrm{P}<0.001$ vs. I/R; ${ }^{\wedge \wedge} \mathrm{P}<0.001$ vs. LBP-15; \#\# $\mathrm{P}<0.001$ vs. RAPA. I/R, ischemia/reperfusion; RAPA, rapamycin; LBP, Lycium barbarum polysaccharide.

markers. The western blotting results revealed that the construction of the cellular I/R model increased the protein expression levels of Beclin 1 and LC3-II/LC3-I, and decreased those of P62 $(\mathrm{P}<0.001)$, whereas treatment of LBP at 60,30 and $15 \mu \mathrm{g} / \mathrm{ml}$ was able to decrease the protein expression levels of Beclin 1 and LC3-II/LC3-I and to increase those of $\mathrm{P} 62$ in $\mathrm{H} 9 \mathrm{C} 2$ cells after 24-h anoxia and 4-h reperfusion $(\mathrm{P}<0.05, \mathrm{P}<0.01, \mathrm{P}<0.001$; Fig. 3A-D), indicating that LBP inhibits I/R-induced autophagic activity.

$R A P A$ partially reverses the inhibitory effect of $L B P$ on autophagy in I/R-treated $H 9 C 2$ cells. To verify if the inhibition of autophagy was involved in the cytoprotective effects of LBP on I/R-induced cardiomyocytes, an autophagy promoter, RAPA, and the lowest concentration $(15 \mu \mathrm{g} / \mathrm{ml})$ of LBP were used to determine the interaction between autophagy and LBP. RAPA treatment alone increased the protein expression levels of Beclin 1 and LC3-II/LC3-I and decreased those of $\mathrm{P} 62$, compared with the $\mathrm{I} / \mathrm{R}$ group $(\mathrm{P}<0.001)$. Moreover, LBP $(15 \mu \mathrm{g} / \mathrm{ml})$ decreased the expression levels of Beclin 1 and LC3-II/LC3-I and the increased expression of P62 in I/R-induced H9C2 cells $(\mathrm{P}<0.001$; Fig. 4A-D). It was also found that LBP $(15 \mu \mathrm{g} / \mathrm{ml})$ treatment reversed RAPA-induced expression changes of these genes $(\mathrm{P}<0.001$; Fig. 4A-D).

RAPA partially reverses $L B P$-induced increase of viability and inhibition of apoptosis, cardiomyocyte damage, inflammation and oxidative stress in I/R-treated H9C2 cells. Furthermore, based on the results of MTT assay and flow cytometry, it was observed that RAPA treatment alone decreased cell viability and increased apoptosis, compared with the I/R group $(\mathrm{P}<0.001)$, and partially reversed the LBP $(15 \mu \mathrm{g} / \mathrm{ml})$-induced increase in viability and inhibition of apoptosis in $\mathrm{I} / \mathrm{R}$-induced H9C2 cells $(\mathrm{P}<0.01, \mathrm{P}<0.001$; Fig. 5A-C). The results of ELISAs showed that after RAPA treatment, the levels of LDH, CK, IL-1 $\beta$, IL-6, TNF- $\alpha$ and MDA were elevated, while that of SOD was lowered, in comparison with those in the I/R group $(\mathrm{P}<0.001)$. Moreover, the LBP $(15 \mu \mathrm{g} / \mathrm{ml})$-induced changes on the levels of these factors were partially reversed $(\mathrm{P}<0.05$, $\mathrm{P}<0.01$; Fig. 5D-J) by RAPA treatment.

$R A P A$ reverses $L B P$-induced promotion on Nrf2 nuclear translocation in $I / R$-induced $H 9 C 2$ cells. A previous study reported the increase of Nrf2 expression during autophagic deficiency (22). As shown in Fig. 6A and B, Nrf2 mRNA and protein expression levels in the nucleus were increased with the treatment of LBP $(15 \mu \mathrm{g} / \mathrm{ml})$ treatment $(\mathrm{P}<0.001)$, but were decreased by RAPA treatment $(\mathrm{P}<0.001)$. On the contrary, LBP treatment $(15 \mu \mathrm{g} / \mathrm{ml})$ was associated with a decreased Nrf2 mRNA and protein expression levels in the cytoplasm $(\mathrm{P}<0.001)$, whilst an opposite trend was observed after RAPA treatment $(\mathrm{P}<0.01, \mathrm{P}<0.001$; Fig. $6 \mathrm{C}$ and $\mathrm{D})$. These results indicated that LBP facilitated the translocation of Nrf2 into the nucleus, while RAPA had an opposite effect and partially 
A

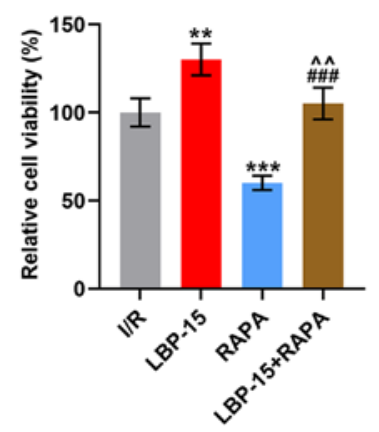

B

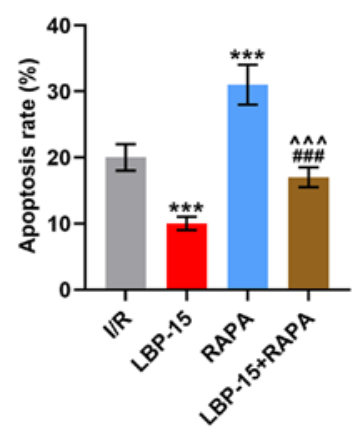

C
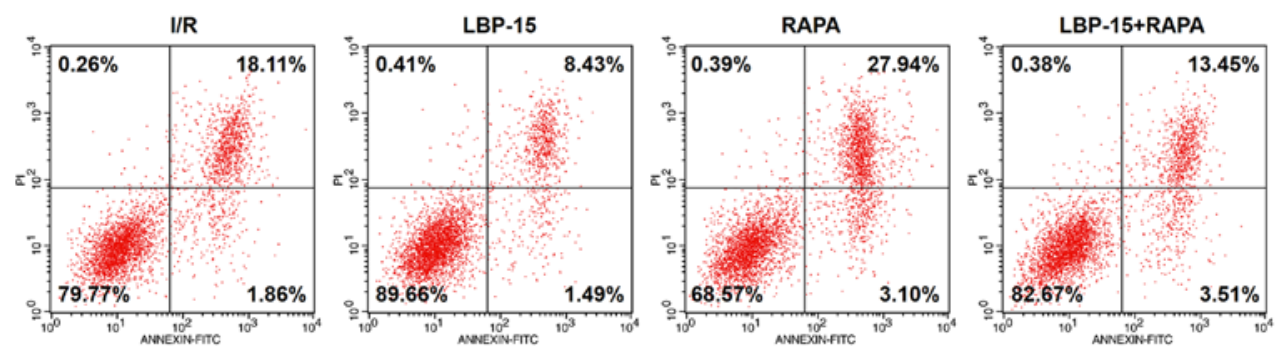

D

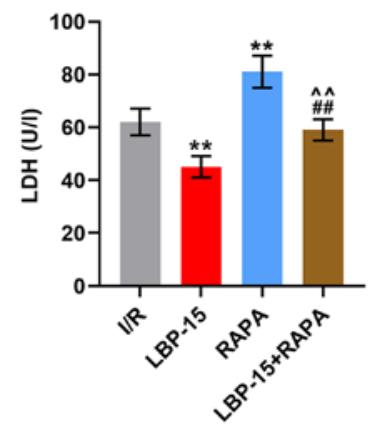

E

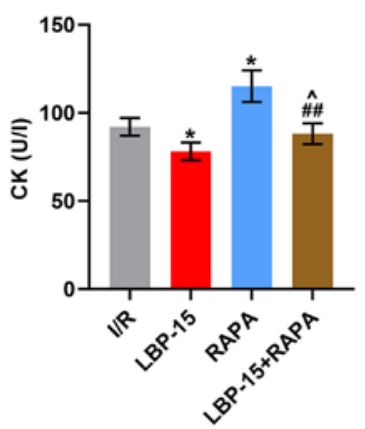

F

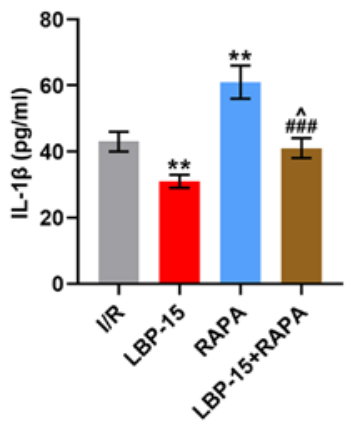

G

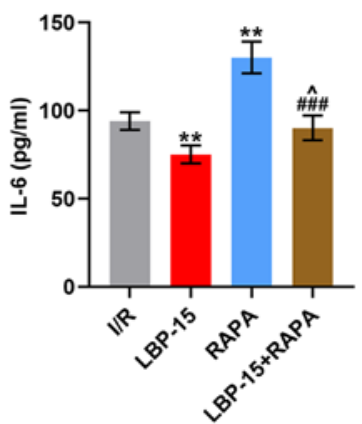

H

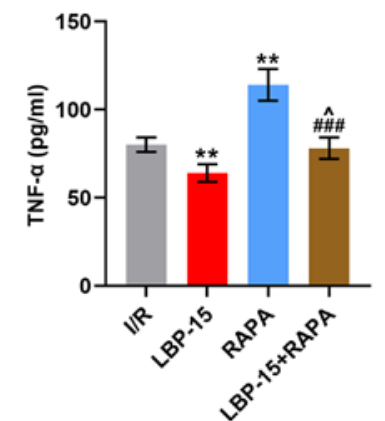

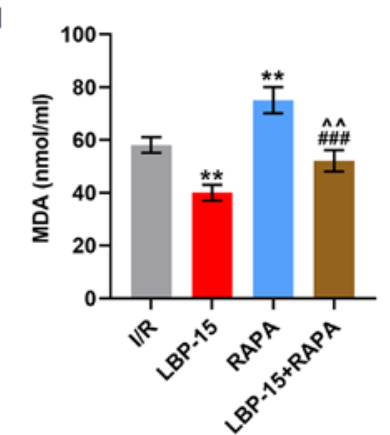

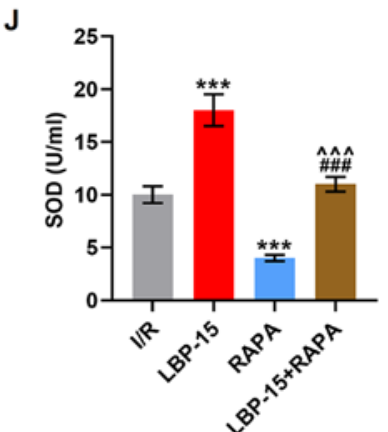

Figure 5. RAPA partially reverses the LBP-induced increase of viability and inhibition of apoptosis, cardiomyocyte damage, inflammation and oxidative stress in I/R-induced H9C2 cells. (A) The viability of I/R-induced H9C2 cells with the treatment of LBP $(15 \mu \mathrm{g} / \mathrm{ml})$ and RAPA in combination or alone was determined using an MTT assay. (B) The apoptosis of I/R-induced H9C2 cells with the treatment of LBP $(15 \mu \mathrm{g} / \mathrm{ml})$ and RAPA in combination or alone was detected via (C) flow cytometry. The levels of (D) LDH, (E) CK, (F) IL-1 $\beta$, (G) IL-6, (H) TNF- $\alpha$, (I) MDA and (J) SOD in I/R-induced H9C2 cells with the treatment of LBP $(15 \mu \mathrm{g} / \mathrm{ml})$ and RAPA in combination or alone were determined via ELISAs. ${ }^{*} \mathrm{P}<0.05,{ }^{* * *} \mathrm{P}<0.01,{ }^{* * * *} \mathrm{P}<0.001$ vs. I/R; ${ }^{\wedge} \mathrm{P}<0.05,{ }^{\wedge} \mathrm{P}<0.01$, ${ }^{\wedge \wedge} \mathrm{P}<0.001$ vs. LBP-15; ${ }^{\# \#} \mathrm{P}<0.01,{ }^{\# \# \#} \mathrm{P}<0.001$ vs. RAPA. I/R, ischemia/reperfusion; LBP, Lycium barbarum polysaccharide; RAPA, rapamycin; LDH, lactate dehydrogenase; CK, creatine kinase; MDA, malondialdehyde; SOD, superoxidase dismutase. 
A

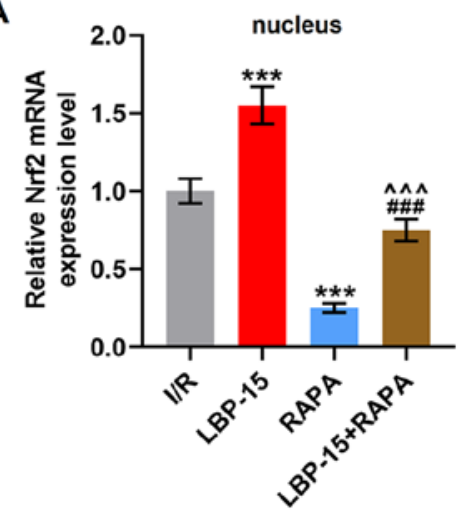

C

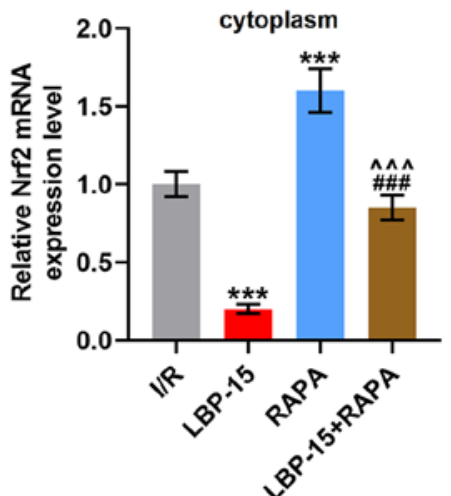

B

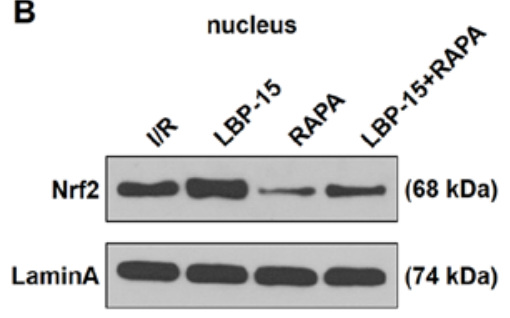

D

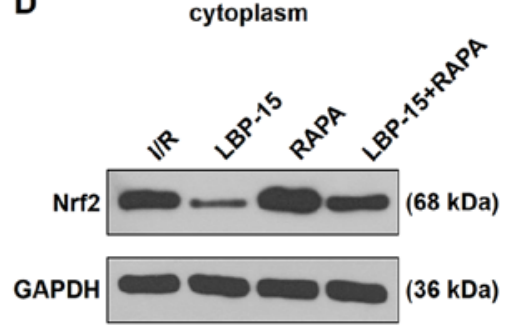

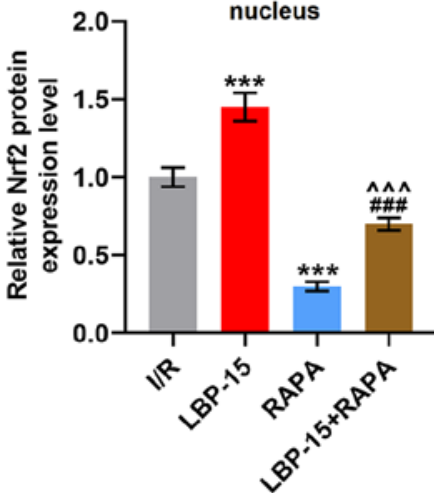

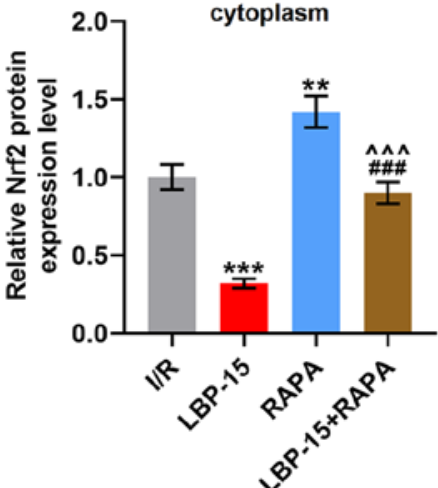

Figure 6. LBP reverses RAPA-induced inhibition on Nrf2 nuclear expression in I/R-induced H9C2 cells. The nuclear (A) mRNA and (B) protein expression levels of Nrf2 in I/R-induced H9C2 cells with LBP $(15 \mu \mathrm{g} / \mathrm{ml})$ and RAPA treatment in combination or alone were calculated via RT-qPCR and western blotting. Lamin A was the internal control. The cytosolic (C) mRNA and (D) protein expression levels of Nrf2 in I/R-induced H9C2 cells treated with LBP $(15 \mu \mathrm{g} / \mathrm{ml})$ and RAPA in combination or alone were measured via RT-qPCR and western blotting, with GAPDH serving as an endogenous reference. ${ }^{* * *} \mathrm{P}<0.01,{ }^{* * *} \mathrm{P}<0.001$ vs. I/R; ${ }^{\wedge \wedge} \mathrm{P}<0.001$ vs. LBP-15; ${ }^{\# \# \#} \mathrm{P}<0.001$ vs. RAPA. Nrf2, nuclear factor-erythroid factor 2 -related factor 2 ; I/R, ischemia/reperfusion; LBP, Lycium barbarum polysaccharide; RAPA, rapamycin; RT-qPCR, reverse transcription-quantitative PCR.

reversed the effects of LPB on the expression levels of both nuclear and cytoplasmic Nrf2 (P<0.001; Fig. 6A-D), suggesting that LPB may inhibit I/R-induced autophagy by facilitating the nuclear translocation of Nrf2.

Nrf2 partially abrogates RAPA-induced decrease of viability, promotion of apoptosis, cardiomyocyte damage, inflammation and oxidative stress in $I / R$-treated $H 9 C 2$ cells. The transfection efficiency of Nrf2 overexpression plasmid in normal H9C2 cells is showed in Fig. 7A. The results demonstrated that the Nrf2 overexpression plasmid significantly increased Nrf2 expression in $\mathrm{H} 9 \mathrm{C} 2$ cells $(\mathrm{P}<0.001)$.

Subsequently, the Nrf2 overexpression plasmid was introduced into I/R-induced and RAPA-treated cardiomyocytes to determine the interaction between Nrf2 and autophagy. Firstly, in comparison with the I/R group, the transfection of Nrf2 overexpression plasmid increased the mRNA and protein expression levels of Nrf2, while RAPA treatment led to a decrease $(\mathrm{P}<0.001$; Fig. $7 \mathrm{~B}$ and $\mathrm{C})$. Furthermore, the effects of Nrf 2 overexpression plasmid on Nrf 2 expression was inhibited by RAPA ( $\mathrm{P}<0.001$; Fig. 7B and $\mathrm{C})$. Then, it was observed that Nrf2 overexpression increased cell viability, inhibited apoptosis, decreased the contents of LDH, CK and MDA, suppressed the release of IL-1 $\beta$, IL- 6 and TNF- $\alpha$, and enhanced SOD activity, compared with the I/R group $(\mathrm{P}<0.001$; Fig. 7D-M). However, these effects induced by Nrf2 overexpression were partially reversed by RAPA treatment $(\mathrm{P}<0.01$; Fig. $7 \mathrm{E}-\mathrm{N})$.

\section{Discussion}

Myocardial I/R injury causes structural and functional changes at the levels of organs, tissues and cells, which leads to cellular destruction (33). During the progression of $\mathrm{I} / \mathrm{R}$, ischemia causes the accumulation of $\mathrm{H}^{+}$and $\mathrm{Ca}^{2+}$, the collapse of mitochondrial membrane potential and the depletion of ATP, leading to the formation of ROS, which in turn activates pro-inflammatory pathways and promotes inflammatory responses (34). The promoted inflammatory responses further induce damage to the tissues surrounding the infarct area by enhancing apoptosis within the cardiomyocyte (34). LBP is a cardio-protective agent with functions that counteract I/R-induced LDH release, inhibition of ATPase activity and promotion of apoptosis in myocardial I/R injury (10). The present study demonstrated that LBP modulated autophagy marker expression so as to exert the protective effects on I/R-treated rats and cardiomyocytes.

Decreased viability and enhanced apoptosis occur in hypoxia/reperfusion (H/R)-treated cardiomyocytes, which is experimentally used to construct a model of myocardial $\mathrm{I} / \mathrm{R}$ injury at cellular levels (35). A previous study reported that LBP could partially reverse the effects of $H / R$ on decreasing the viability and promoting the apoptosis of H9C2 cells (36). The current study established I/R models both in vivo and in vitro, during which LBP treatment at 15,30 and $60 \mu \mathrm{g} / \mathrm{ml}$ was used. The results demonstrated that LBP counteracted 

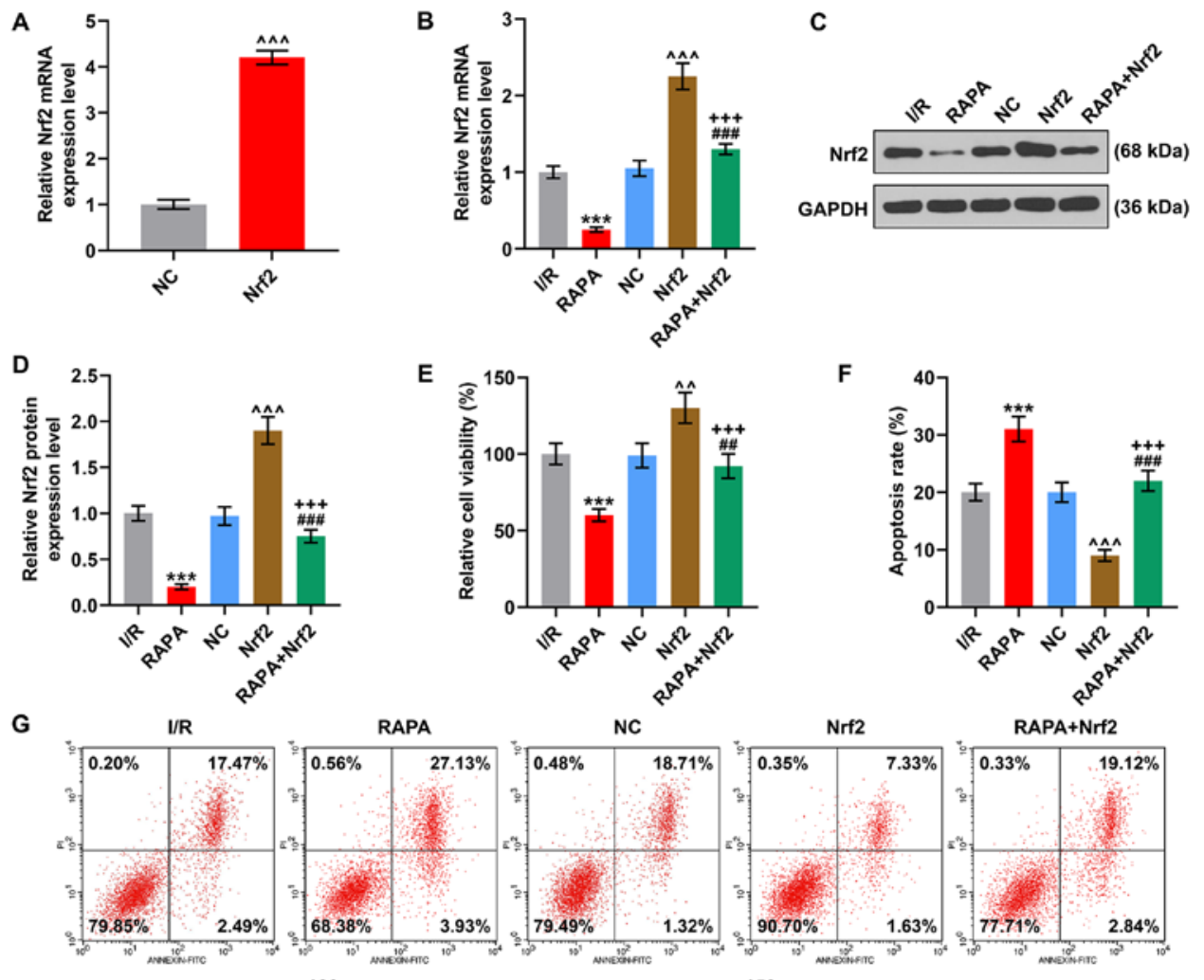

H
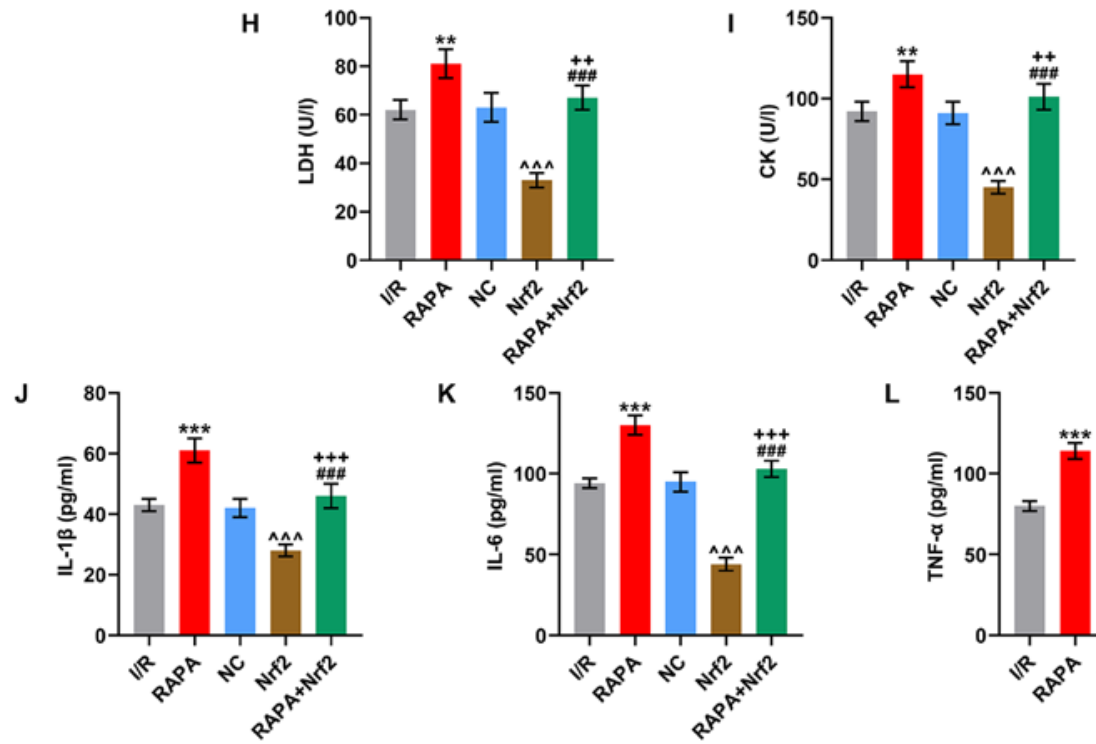

K

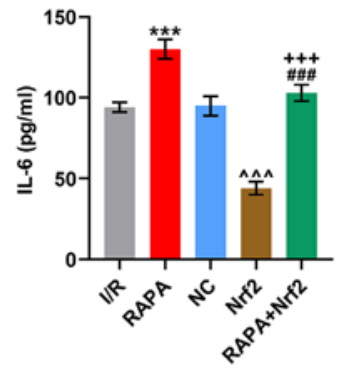

L

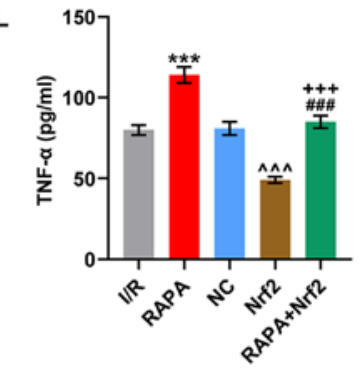

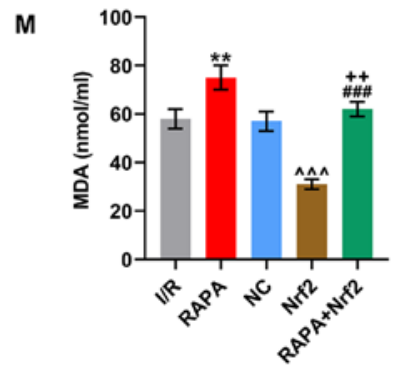

N

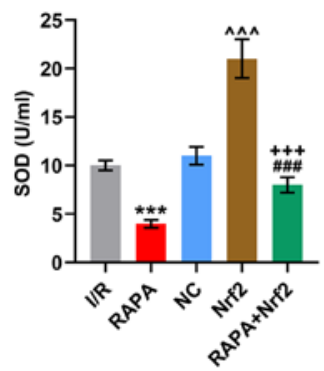

Figure 7. Nrf2 partially reverses RAPA-induced decrease of viability, promotion of apoptosis, cardiomyocyte damage, inflammation and oxidative stress in I/R-induced H9C2 cells. (A) The transfection efficiency of Nrf2 overexpression plasmid in normal H9C2 cells. The (B) mRNA and (C and D) protein expression levels of Nrf2 in I/R-induced H9C2 cells with transfection of Nrf2 overexpression plasmid, RAPA treatment or the combined management were quantified by reverse transcription-quantitative PCR and western blotting. GAPDH was used as internal reference. (E) The viability of I/R-induced H9C2 cells undergoing transfection of Nrf2 overexpression plasmid, RAPA treatment or the combined management was determined using an MTT assay. (F) The apoptosis of I/R-induced H9C2 cells after the transfection of Nrf2 overexpression plasmid, RAPA treatment or the combined management was detected via (G) flow cytometry. The levels of (H) LDH, (I) CK, (J) IL-1 $\beta$, (K) IL-6, (L) TNF- $\alpha$, (M) MDA and (N) SOD in I/R-induced H9C2 cells undergoing transfection of Nrf2 overexpression plasmid, RAPA treatment or the combined management were calculated using ELISAs. ${ }^{* *} \mathrm{P}<0.01,{ }^{* * * *} \mathrm{P}<0.001 \mathrm{vs}$. I/R; ${ }^{\wedge} \mathrm{P}<0.01,{ }^{\wedge \wedge} \mathrm{P}<0.001 \mathrm{vs}$. NC; ${ }^{++} \mathrm{P}<0.01,{ }^{+++} \mathrm{P}<0.001 \mathrm{vs}$. RAPA; ${ }^{\# \#} \mathrm{P}<0.01$,

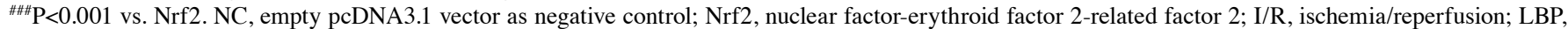
Lycium barbarum polysaccharide; RAPA, rapamycin; LDH, lactate dehydrogenase; CK, creatine kinase; MDA, malondialdehyde; SOD, superoxidase dismutase. 
I/R-induced heart malfunction and histopathological abnormalities in vivo. Moreover, in line with a previous finding concerning the effects LBP on the phenotypic changes of I/R-induced cardiomyocytes (36), the present study observed that LBP exerted antagonistic effects against the decreased viability and the increased apoptosis in H/R-induced H9C2 cells.

CK serves a crucial role in regulating ATP preservation, which is positively correlated with an improved contractile function in I/R-induced rats $(37,38)$. During the progression of $\mathrm{I} / \mathrm{R}$, the release of $\mathrm{CK}$, as well as $\mathrm{LDH}$ and cTnT, two main inducible factors of myocardial injury, from the myocardium into the blood are increased. As such, inhibiting the releases of $\mathrm{LDH}$ and $\mathrm{CK}$ can exert a cardio-protective effect on I/R-induced ischemic hearts of rats (32). Furthermore, suppressing inflammatory cytokines (IL-1 $\beta$, IL-6 and TNF- $\alpha$ ) produced during $\mathrm{I} / \mathrm{R}$-induced inflammatory responses in the myocardium is also contributory to cardio-protection against I/R injury (39). I/R also induces the production of excessive ROS, which then oxidizes cellular proteins, membrane lipids and nucleic acids (40) and further leads to the aggravation of myocardial I/R injury, with increased MDA level and decreased SOD (35). Decreased MDA and increased SOD levels have been indicated to be associated with ameliorated myocardial I/R injury (41). A prior study has revealed that LBP, as an oxidative agent, reduces cardiotoxicity induced by doxorubicin and leads to the decreased CK and MDA levels and increased those of SOD (42). LBP can also decrease the expression levels of inflammatory factors (IL- 6 and TNF- $\alpha$ ) in heart tissues, based on the results of a study where the effects of LBP on cardiac hypertrophy in diabetic rats were discussed (16). Similar to the effects of LBP shown in these findings, the present study identified that LBP counteracted the effects of I/R both in vivo and in vitro by abolishing the I/R-induced changes on the levels of all these aforementioned indexes or factors, suggesting that LBP alleviated the cell injury, inflammatory responses and oxidative stress in I/R-induced cardiomyocytes.

Autophagy preserves cardiac structure and function at baseline by inhibiting misfolded proteins and damaged organelles in physiological condition, and is further activated during stress, thereby limiting cardiac injury in numerous pathological conditions $(43,44)$. For example, autophagy maintains cardiac function under ischemia and starvation conditions, and reduces myocardial damage (45). However, an excessive activation in autophagy under ischemia/reperfusion has been reported, where autophagy may facilitate myocardial injury (46-49). Moreover, an increase in autophagy activity has been observed in the subacute and chronic stages of cardiac ischemia in a mouse model with myocardial infarction $(50,51)$. Autophagy is a mechanism induced by the oxidative stress in myocardial I/R injury and causes the death of cardiomyocyte (4). Pharmacological inhibition of autophagy can help prevent I/R-induced heart failure by improving cardio-function and alleviating myocardial injury by reversely regulating I/R-induced increases of $\mathrm{LDH}, \mathrm{CK}$, ROS and MDA and decreases of SOD (21). Thus, appropriate inhibition of autophagy could be a novel therapeutic method for I/R injury.

Hence, in the present study, RAPA, an activator of autophagy, was hypothesized to abolish the cardio-protective effects of LBP against I/R injury. LBP was previously found to counteract the oxygen glucose deprivation/reperfusion-induced upregulated expression of LC3-II/LC3-I and Beclin 1 and downregulated expression of P62 to suppress autophagic cell death in primary hippocampal neurons (27). In accordance with this finding in which the autophagy-repressive effect of LBP has been indicated, the present study demonstrated that LBP counteracted the effects of I/R on decreasing the expression of LC3-II/LC3-I and Beclin 1 and increasing that of P62. More notably, LBP exerted inhibitory effects on RAPA-potentiated autophagy in I/R-treated H9C2 cells, while RAPA partially reversed the suppressive effects of LBP on autophagy, which collectively indicated that the cardio-protective effects of LBP against I/R-induced injury is, at least partially, dependent on the inhibition of autophagy.

Inhibited Nrf2 expression is evidenced in PM2.5-induced autophagy of A549 cells, according to a study by Dai et al (22). Similar to Dai's findings, the present study identified that both nuclear translocation and nuclear expression of $\mathrm{Nrf} 2$ were inhibited by RAPA-induced autophagy in I/R-treated cardiomyocytes, which suggests that LBP-induced autophagy inhibition can lead to Nrf2 activation. Furthermore, previous studies have shown that the activation of Nrf2 induced by LBP reduces ROS production and lipid peroxide level, but elevates SOD levels in human skin fibroblast cells (52), as well as attenuates hyperoxic acute lung injury by inhibiting the infiltration of IL-1 $\beta$ and IL- 6 into the lungs of mice (53). Likewise, the present study revealed that LBP facilitated the nuclear translocation of Nrf2.

Nrf2, a member of the cap ' $n$ ' collar subfamily of basic-region leucine zipper (54), is involved in the regulation of antioxidant responses by inducing the expression of antioxidative genes, such as heme oxygenase-1, glutathione peroxidase and SOD (55). The activation of Nrf2 can exert a cardio-protective effect via both the suppression of oxidization and inflammation, and the potential regulation of autophagy (56). Increased Nrf2 expression in the nucleus is associated with the alleviation of H/R-induced impaired viability and enhanced apoptosis of cardiomyocytes (57), as well as improved cardiac function, reduced myocardial infarction area, decreased levels of CK, LDH and MDA and increased SOD levels in I/R-treated rats (58). Moreover, it is associated with the inhibited production of IL-6 and TNF- $\alpha$ (59). Based on the present results, it was found that Nrf2 expression inhibited apoptosis and the levels of CK, LDH, IL-1 $\beta$, IL-6, TNF- $\alpha$ and MDA, and increased SOD levels; the effects of which were similar to the aforementioned studies. Taken together, the current results indicated that LBP inhibited autophagy to activate Nrf2 so as to exert its cardio-protective effects against I/R-induced injury.

However, there are several potential limitations to the present study. For instance, there was lack of more direct evidence to confirm autophagy using imaging tools, such as scanning electron microscopy and transmission electron microscopy. Most polysaccharides cannot be completely digested by the human digestive system, so the natural polysaccharides mainly exert their benefits on health by slowing gastric emptying, regulating the gut microbe structure, influencing microbial fermentation as substrates, improving bowel function, as well as protecting the immune system (60). 
As a natural polysaccharide, LPB may also not be digested completely by the human alimentary system. Natural polysaccharides are favorable for the proliferation of short chain fatty acid-producing bacteria, the presence of which can improve the intestinal microenvironment (61). For example, fermented Yupingfeng polysaccharides can effectively improve the intestinal flora homeostasis (62). Additionally, modulating the gut microbiota is a potential treatment for cardiovascular diseases (63). A previous study reported that LBP reduced intestinal permeability and inflammatory cytokine levels, maintained a healthy intestinal microenvironment, and alleviated myocardial injury 13). Therefore, the mechanism of the protective effect of LBP on myocardial I/R injury may be associated with its role in the regulation of intestinal microenvironment

In conclusion, the present study identified that LBP counteracts H/R-induced decrease of viability, promotion of apoptosis, inflammation and oxidative stress in cardiomyocytes by inhibiting autophagy via the activation of $\mathrm{Nrf} 2$, thus attenuating myocardial I/R injury.

\section{Acknowledgements}

Not applicable.

\section{Funding}

This work was supported by the Zhejiang Province Science Research Foundation of Traditional Chinese Medicine (grant no. 2020ZB152).

\section{Availability of data and materials}

The datasets used and/or analyzed during the current study are available from the corresponding author on reasonable request.

\section{Authors' contributions}

HP made substantial contributions to conception and design, drafted the article and critically revised the manuscript for important intellectual content. LN, YW, LC, XZ and YZ were responsible for data acquisition, analysis and interpretation. HP and YZ confirm the authenticity of all the raw data. All authors have read and approved the final version of the manuscript. All authors agree to be accountable for all aspects of the work in ensuring that questions related to the accuracy or integrity of the work are appropriately investigated and resolved.

\section{Ethics approval and consent to participate}

All animal experiments were performed in accordance with the guidelines for the care and use of laboratory animals (National Institutes of Health). This study was approved by the Committee of Experimental Animals of Zhejiang Province Animal Center (approval no. DC201901203). Every effort was made to minimize pain and discomfort to the animals. The animals experiments were performed in Zhejiang Province Animal Center.

\section{Patient consent for publication}

Not applicable.

\section{Competing interests}

The authors declare that they have no competing interests.

\section{References}

1. Yellon DM and Hausenloy DJ: Myocardial reperfusion injury. N Engl J Med 357: 1121-1135, 2007.

2. Lindsey ML, Bolli R, Canty JM Jr, Du XJ, Frangogiannis NG, Frantz S, Gourdie RG, Holmes JW, Jones SP, Kloner RA, et al: Guidelines for experimental models of myocardial ischemia and infarction. Am J Physiol Heart Circ Physiol 314: H812-H838, 2018.

3. Esposito ML, Zhang Y, Qiao X, Reyelt L, Paruchuri V, Schnitzler GR, Morine KJ, Annamalai SK, Bogins C, Natov PS, et al: Left ventricular unloading before reperfusion promotes functional recovery after acute myocardial infarction. J Am Coll Cardiol 72: 501-514, 2018.

4. Wu MY, Yiang GT, Liao WT, Tsai AP, Cheng YL, Cheng PW, $\mathrm{Li} \mathrm{CY}$ and Li CJ: Current mechanistic concepts in ischemia and reperfusion injury. Cell Physiol Biochem 46: 1650-1667, 2018.

5. Kunecki M, Płazak W, Podolec P and Gołba KS: Effects of endogenous cardioprotective mechanisms on ischemia-reperfusion injury. Postepy Hig Med Dosw 71: 20-31, 2017.

6. Galagudza MM, Blokhin IO, Shmonin AA and Mischenko KA: Reduction of myocardial ischemia-reperfusion injury with preand postconditioning: Molecular mechanisms and therapeutic targets. Cardiovasc Hematol Disord Drug Targets 8: 47-65, 2008.

7. Yu P, Zhang J, Yu S, Luo Z, Hua F, Yuan L, Zhou Z, Liu Q, $\mathrm{Du} X$, Chen S, et al: Protective effect of sevoflurane postconditioning against cardiac ischemia/reperfusion injury via ameliorating mitochondrial impairment, oxidative stress and rescuing autophagic clearance. PLoS One 10: e0134666, 2015.

8. Li J, Xiang X, Gong X, Shi Y, Yang J and Xu Z: Cilostazol protects mice against myocardium ischemic/reperfusion injury by activating a PPAR $\gamma / \mathrm{JAK} 2 / \mathrm{STAT} 3$ pathway. Biomed Pharmacother 94: 995-1001, 2017.

9. Weinreuter M, Kreusser MM, Beckendorf J, Schreiter FC, Leuschner F, Lehmann LH, Hofmann KP, Rostosky JS, Diemert N, Xu C, et al: CaM Kinase II mediates maladaptive post-infarct remodeling and pro-inflammatory chemoattractant signaling but not acute myocardial ischemia/reperfusion injury. EMBO Mol Med 6: 1231-1245, 2014.

10. Hou YM, Wang J and Zhang XZ: Lycium barbarum polysaccharide exhibits cardioprotection in an experimental model of ischemia-reperfusion damage. Mol Med Rep 15: 2653-2658, 2017.

11. Varoni MV, Pasciu V, Gadau SD, Baralla E, Serra E, Palomba D and Demontis MP: Possible antioxidant effect of Lycium barbarum polysaccharides on hepatic cadmium-induced oxidative stress in rats. Environ Sci Pollut Res Int 24: 2946-2955, 2017.

12. Bo R, Zheng S, Xing J, Luo L, Niu Y, Huang Y, Liu Z, Hu Y, Liu J, Wu Y, et al: The immunological activity of Lycium barbarum polysaccharides liposome in vitro and adjuvanticity against PCV2 in vivo. Int J Biol Macromol 85: 294-301, 2016.

13. Zhang XJ, Yu HY, Cai YJ and Ke M: Lycium barbarum polysaccharides inhibit proliferation and migration of bladder cancer cell lines BIU87 by suppressing Pi3K/AKT pathway. Oncotarget 8: 5936-5942, 2017.

14. Li SY, Yang D, Yeung CM, Yu WY, Chang RC, So KF, Wong D and Lo AC: Lycium barbarum polysaccharides reduce neuronal damage, blood-retinal barrier disruption and oxidative stress in retinal ischemia/reperfusion injury. PLoS One 6: e16380, 2011.

15. Xiao J, Xing F, Huo J, Fung ML, Liong EC, Ching YP, $\mathrm{Xu}$ A, Chang RC, So KF and Tipoe GL: Lycium barbarum polysaccharides therapeutically improve hepatic functions in non-alcoholic steatohepatitis rats and cellular steatosis model. Sci Rep 4: 5587, 2014.

16. Liu Q, Han Q, Lu M, Wang H and Tang F: Lycium barbarum polysaccharide attenuates cardiac hypertrophy, inhibits calpain-1 expression and inhibits NF- $\kappa$ B activation in streptozotocin-induced diabetic rats. Exp Ther Med 18: 509-516, 2019. 
17. Levine B and Kroemer G: Autophagy in the pathogenesis of disease. Cell 132: 27-42, 2008.

18. Xie Z and Klionsky DJ: Autophagosome formation: Core machinery and adaptations. Nat Cell Biol 9: 1102-1109, 2007.

19. Tanida I, Ueno T and Kominami E: LC3 conjugation system in mammalian autophagy. Int J Biochem Cell Biol 36: 2503-2518, 2004.

20. Ma S, Wang Y, Chen Y and Cao F: The role of the autophagy in myocardial ischemia/reperfusion injury. Biochim Biophys Acta 1852: 271-276, 2015

21. Wu S, Chang G, Gao L, Jiang D, Wang L, Li G, Luo X, Qin S Guo $X$ and Zhang D: Trimetazidine protects against myocardial ischemia/reperfusion injury by inhibiting excessive autophagy. J Mol Med (Berl) 96: 791-806, 2018.

22. Dai P, Shen D, Shen J, Tang Q, Xi M, Li Y and Li C: The roles of Nrf2 and autophagy in modulating inflammation mediated by TLR4-NFאB in A549 cell exposed to layer house particulate matter 2.5 (PM2.5). Chemosphere 235: 1134-1145, 2019.

23. National Research Council. 2011. Guide for the Care and Use of Laboratory Animals: Eighth Edition. Washington, DC: The National Academies Press. https://doi.org/10.17226/12910.

24. Liu SY, Chen L, Li XC, Hu QK and He LJ: Lycium barbarum polysaccharide protects diabetic peripheral neuropathy by enhancing autophagy via mTOR/p70S6K inhibition in Streptozotocin-induced diabetic rats. J Chem Neuroanat 89: 37-42, 2018.

25. Du M, Hu X, Kou L, Zhang B and Zhang C: Lycium barbarum Polysaccharide Mediated the Antidiabetic and Antinephritic Effects in Diet-Streptozotocin-Induced Diabetic Sprague Dawley Rats via Regulation of NF-кB. BioMed Res Int 2016: 3140290 2016.

26. Zhao Y, Guo R, Li L, Li S, Fan G, Zhao X and Wang Y: Tongmai formula improves cardiac function via regulating mitochondrial quality control in the myocardium with ischemia/reperfusion injury. Biomed Pharmacother 132: 110897, 2020.

27. Yu Y, Wu X, Pu J, Luo P, Ma W, Wang J, Wei J, Wang Y and Fei Z: Lycium barbarum polysaccharide protects against oxygen glucose deprivation/reoxygenation-induced apoptosis and autophagic cell death via the PI3K/Akt/mTOR signaling pathway in primary cultured hippocampal neurons. Biochem Biophys Res Commun 495: 1187-1194, 2018

28. Xu Q, Li X, Lu Y, Shen L, Zhang J, Cao S, Huang X, Bin J and Liao Y: Pharmacological modulation of autophagy to protect cardiomyocytes according to the time windows of ischaemia/ reperfusion. Br J Pharmacol 172: 3072-3085, 2015.

29. Livak KJ and Schmittgen TD: Analysis of relative gene expression data using real-time quantitative PCR and the 2(-Delta Delta C(T)) method. Methods 25: 402-408, 2001.

30. Wallert M, Ziegler M, Wang X, Maluenda A, Xu X, Yap ML, Witt R, Giles C, Kluge S, Hortmann M, et al: $\alpha$-Tocopherol preserves cardiac function by reducing oxidative stress and inflammation in ischemia/reperfusion injury. Redox Biol 26: 101292,2019

31. Wu T, Jiang N, Ji Z and Shi G: The IRE1 signaling pathway is involved in the protective effect of low-dose LPS on myocardial ischemia-reperfusion injury. Life Sci 231: 116569, 2019.

32. Amani M, Jeddi S, Ahmadiasl N, Usefzade N and Zaman J: effect of HEMADO on level of CK-MB and LDH enzymes after ischemia/reperfusion injury in isolated rat heart. Bioimpacts 3 : 101-104, 2013.

33. Lee YR, Chen SH, Lin CY, Chao WY,Lim YP, Yu HI and Lu CH:In vitro antitumor activity of aloperine on human thyroid cancer cells through caspase-dependent apoptosis. Int J Mol Sci 19: 312, 2018.

34. Frank A, Bonney M, Bonney S, Weitzel L, Koeppen M and Eckle T: Myocardial ischemia reperfusion injury: From basic science to clinical bedside. Semin Cardiothorac Vasc Anesth 16 123-132, 2012

35. Zhang W, Li Y and Wang P: Long non-coding RNA-ROR aggravates myocardial ischemia/reperfusion injury. Braz J Med Biol Res 51: e6555, 2018.

36. Li Q, Zhang Z, Li H, Pan X, Chen S, Cui Z, Ma J, Zhou Z and Xing B: Lycium barbarum polysaccharides protects H9c2 cells from hypoxia-induced injury by down-regulation of miR-122. Biomed Pharmacother 110: 20-28, 2019.

37. Cao F, Zervou S and Lygate CA: The creatine kinase system as a therapeutic target for myocardial ischaemia-reperfusion injury. Biochem Soc Trans 46: 1119-1127, 2018

38. Wang DS, Yan LY, Yang DZ, Lyu Y, Fang LH, Wang SB and Du GH: Formononetin ameliorates myocardial ischemia/reperfusion injury in rats by suppressing the ROS-TXNIP-NLRP3 pathway. Biochem Biophys Res Commun 525: 759-766, 2020.
39. Bai Y, Li Z, Liu W, Gao D, Liu M and Zhang P: Biochanin A attenuates myocardial ischemia/reperfusion injury through the TLR4/NF-kB/NLRP3 signaling pathway. Acta Cir Bras 34: e201901104, 2019.

40. Balakumar P and Sharma NK: Healing the diabetic heart: Does myocardial preconditioning work? Cell Signal 24: 53-59, 2012.

41. Yu L, Gong B, Duan W, Fan C, Zhang J, Li Z, Xue X, Xu Y, Meng D, $\mathrm{Li} \mathrm{B}$, et al: Melatonin ameliorates myocardial ischemia/reperfusion injury in type 1 diabetic rats by preserving mitochondrial function: Role of AMPK-PGC-1 $\alpha$-SIRT3 signaling. Sci Rep 7: 41337, 2017.

42. Xin YF, Wan LL, Peng JL and Guo C: Alleviation of the acute doxorubicin-induced cardiotoxicity by Lycium barbarum polysaccharides through the suppression of oxidative stress. Food Chem Toxicol 49: 259-264, 2011

43. Nakai A, Yamaguchi O, Takeda T, Higuchi Y, Hikoso S, Taniike M, Omiya S, Mizote I, Matsumura Y, Asahi M, et al: The role of autophagy in cardiomyocytes in the basal state and in response to hemodynamic stress. Nat Med 13: 619-624, 2007.

44. Ikeda Y, Shirakabe A, Maejima Y, Zhai P, Sciarretta S, Toli J, Nomura M, Mihara K, Egashira K, Ohishi M, et al: Endogenous Drp1 mediates mitochondrial autophagy and protects the heart against energy stress. Circ Res 116: 264-278, 2015.

45. Sciarretta S, Zhai P, Shao D, Maejima Y, Robbins J, Volpe M, Condorelli G and Sadoshima J: Rheb is a critical regulator of autophagy during myocardial ischemia: Pathophysiological implications in obesity and metabolic syndrome. Circulation 125: 1134-1146, 2012.

46. Matsui Y, Takagi H, Qu X, Abdellatif M, Sakoda H, Asano T, Levine B and Sadoshima J: Distinct roles of autophagy in the heart during ischemia and reperfusion: Roles of AMP-activated protein kinase and Beclin 1 in mediating autophagy. Circ Res 100: 914-922, 2007.

47. Wei C, Li H, Han L, Zhang L and Yang X: Activation of autophagy in ischemic postconditioning contributes to cardioprotective effects against ischemia/reperfusion injury in rat hearts. J Cardiovasc Pharmacol 61: 416-422, 2013.

48. Ma X, Liu H, Foyil SR, Godar RJ, Weinheimer CJ and Diwan A: Autophagy is impaired in cardiac ischemia-reperfusion injury. Autophagy 8: 1394-1396, 2012.

49. Huang Z, Han Z, Ye B, Dai Z, Shan P, Lu Z, Dai K, Wang C and Huang W: Berberine alleviates cardiac ischemia/reperfusion injury by inhibiting excessive autophagy in cardiomyocytes. Eur J Pharmacol 762: 1-10, 2015.

50. Kanamori H, Takemura G, Goto $K$, Maruyama $R$, Ono K, Nagao K, Tsujimoto A, Ogino A, Takeyama T, Kawaguchi T, et al: Autophagy limits acute myocardial infarction induced by permanent coronary artery occlusion. Am J Physiol Heart Circ Physiol 300: H2261-H2271, 2011.

51. Kanamori H, Takemura G, Goto K, Maruyama R, Tsujimoto A, Ogino A, Takeyama T, Kawaguchi $\mathrm{T}$, Watanabe $\mathrm{T}$, Fujiwara T, et al: The role of autophagy emerging in postinfarction cardiac remodelling. Cardiovasc Res 91: 330-339, 2011.

52. Liang B, Peng L, Li R, Li H, Mo Z, Dai X, Jiang N, Liu Q, Zhang E, Deng H, et al: Lycium barbarum polysaccharide protects HSF cells against ultraviolet-induced damage through the activation of Nrf2. Cell Mol Biol Lett 23: 18, 2018.

53. Zheng G, Ren H, Li H, Li X, Dong T, Xu S, Yan Y, Sun B, Bai J and Li Y: Lycium barbarum polysaccharide reduces hyperoxic acute lung injury in mice through Nrf2 pathway. Biomed Pharmacother 111: 733-739, 2019.

54. Itoh K, Igarashi K, Hayashi N, Nishizawa M and Yamamoto M: Cloning and characterization of a novel erythroid cell-derived CNC family transcription factor heterodimerizing with the small Maf family proteins. Mol Cell Biol 15: 4184-4193, 1995.

55. Magesh S, Chen Y and Hu L: Small molecule modulators of Keap1-Nrf2-ARE pathway as potential preventive and therapeutic agents. Med Res Rev 32: 687-726, 2012.

56. Shen Y, Liu X, Shi J and Wu X: Involvement of Nrf2 in myocardial ischemia and reperfusion injury. Int $\mathrm{J}$ Biol Macromol 125: 496-502, 2019.

57. Dang X,Zhang R, Peng Z, Qin Y, Sun J, Niu Z and Pei H: HIPK2 overexpression relieves hypoxia/reoxygenation-induced apoptosis and oxidative damage of cardiomyocytes through enhancement of the Nrf2/ARE signaling pathway. Chem Biol Interact 316: 108922, 2020.

58. Cheng L, Jin Z, Zhao R, Ren K, Deng C and Yu S: Resveratrol attenuates inflammation and oxidative stress induced by myocardial ischemia-reperfusion injury: Role of Nrf2/ARE pathway. Int J Clin Exp Med 8: 10420-10428, 2015. 
59. Yu H, Shi L, Zhao S, Sun Y, Gao Y, Sun Y and Qi G: Triptolide attenuates myocardial ischemia/reperfusion injuries in rats by inducing the activation of $\mathrm{Nrf} 2 / \mathrm{HO}-1$ defense pathway. Cardiovasc Toxicol 16: 325-335, 2016.

60. Zhang T, Yang Y, Liang Y, Jiao X and Zhao C: Beneficial effect of intestinal fermentation of natural polysaccharides. Nutrients 10: 1055, 2018.

61. Tang C, Ding R, Sun J, Liu J, Kan J and Jin C: The impacts of natural polysaccharides on intestinal microbiota and immune responses - a review. Food Funct 10: 2290-2312, 2019.

62. Sun H, Ni X, Song X, Wen B, Zhou Y, Zou F, Yang M, Peng Z, Zhu H, Zeng Y, et al: Fermented Yupingfeng polysaccharides enhance immunity by improving the foregut microflora and intestinal barrier in weaning rex rabbits. Appl Microbiol Biotechnol 100: 8105-8120, 2016.
63. Zhang Z, Liu H, Yu B, Tao H, Li J, Wu Z, Liu G, Yuan C, Guo L and Cui B: Lycium barbarum polysaccharide attenuates myocardial injury in high-fat diet-fed mice through manipulating the gut microbiome and fecal metabolome. Food research international (Ottawa, Ont) 138: 109778, 2020.

(i) () $\odot$ This work is licensed under a Creative Commons Attribution-NonCommercial-NoDerivatives 4.0 International (CC BY-NC-ND 4.0) License. 